\title{
LA ORDEN DE SERVICIOS 3/2018: ¿UN INSTRUMENTO PARA MEDIR EL RIESGO DE RADICALISMO VIOLENTO EN PRISIÓN?
}

\author{
Jesús Carreras Aguerri * \\ Carlos Fernández Abad**
}

Resumen: El presente artículo tiene por objeto principal examinar el instrumento para medir el riesgo de radicalismo violento que introduce la Orden de Servicios 3/2018 de Instituciones Penitenciarias como parte de la respuesta que ha ofrecido el sistema penitenciario español ante el fenómeno de la radicalización islamista en las prisiones. En este sentido, se argumenta que, además de ser una pura construcción social, la figura del radical resultante presenta claras deficiencias que se traducen en una clara criminalización del

Recibido: agosto 2020. Aceptado: febrero 2021

* Profesor Asociado. ORCID: https://orcid.org/0000-0002-7730-8527

Centro Crímina, Universidad Miguel Hernández de Elche. Dirección: Av. De la Universidad, s/n, 03202. Elche. Email: j.aguerri@crimina.es.

** Profesor Ayudante Doctor. ORCID: https://orcid.org/0000-0002-6392-7597

Facultad de Ciencias Jurídicas y Sociales de la Universidad Rey Juan Carlos. Dirección Calle Tulipán, s/n. 28933. Móstoles (Madrid). Email: carlos.abad@urjc.es 
pensamiento y en la adopción de una política basada fundamentalmente en la neutralización de la peligrosidad que, lejos de contribuir a prevenir la radicalización, no hace sino potenciar las causas que alimentan su existencia.

Palabras clave: radicalización; prisión; sistema penitenciario español; riesgo; neutralización.

\author{
THE 3/2018 PRISON SERVICE INSTRUCTION: AN \\ INSTRUMENT TO MEASURE THE RISK OF VIOLENT \\ RADICALIZATION IN PRISON?
}

\begin{abstract}
This paper seeks to analyse the instrument to measure the risk of violent radicalization in prison which the 3/2018 Prison Service Instruction has introduced as a part of the Spanish Prison System's response against Islamist radicalization in prisons. In this sense, it is argued that, besides being a pure social construction, the resulting label of "the radical" presents serious deficiencies which imply a clear criminalization of thought and the adoption of a policy fundamentally based on the neutralization of dangerousness that, far from helping to prevent radicalization, it enhances the causes which nourished its existence.
\end{abstract}

Keywords: radicalization; prison; The Spanish Prison System; risk; neutralization.

\title{
1. Introducción
}

Durante los últimos quince años, la radicalización islamista ha sido un fenómeno ampliamente estudiado por el mundo académico ${ }^{1}$. En este sentido, han sido numerosas

1 Ahora bien, conviene advertir que, tal y como señala SEDGWICK, la popularidad de este término es bastante reciente. En este sentido, con anterioridad al año 2001, las referencias al mismo eran escasas tanto en los medios de comunicación como en la literatura científica. Entre el año 2005 y 2007, sin embargo, su uso se intensifica y llega a institucionalizarse a raíz de la emergencia del denominado home-grown terrorism. Para una mayor detalle sobre esta evolución, véase, SEDGWICK, M.

"The concept of Radicalization as a Source of Confusion", en Terrorism 
las publicaciones que, desde perspectivas muy diferentes, han abordado cuestiones como las causas subyacentes de este proceso, las diferentes fases que lo componen o los espacios en los que generalmente tiene lugar ${ }^{2}$. Al mismo tiempo, este término también ha devenido central en el campo de lo político, siendo comúnmente referido en los diferentes planes y estrategias de lucha contra el terrorismo ${ }^{3}$.

and Political Violence, núm.22, 2010, pp.479-494. Como contrapartida, aquellos enfoques que priorizan el análisis de los factores estructurales para explicar el terrorismo habrían perdido vigencia durante los últimos años (KUNDNANI, A., "Radicalisation: the journey of a concept", en Race \& Class, vol.54, pp.3-25).

2 Entre otros muchos, SILKE, A. "Holy Warriors: Exploring the Psychological Processes of Jihadi Radicalization", en European Journal of Criminology, vol.5, núm.1, 2008, pp.99-123; SAGEMAN, M. Leaderless Jihad: Terror Networks in the Twenty-First Century, Philadelphia, University of Pennsylvania Press. 2008; KING, M., \& TAYLOR, D. M. "The Radicalization of Homegrown Jihadists: A Review of Theoretical Models and Social Psychological Evidence", en Terrorism and Political Violence, núm. 4(23), 2011, pp: 602-622. En lo que se refiere de forma específica al contexto nacional, por ejemplo, véase, ALONSO PASCUAL, R. "Procesos de radicalización y reclutamiento en las redes de terrorismo yihadista", en Cuadernos de Estrategia, núm.141, pp.21-68; JORDÁN ENAMORADO, J. "Procesos de radicalización yihadista en España: Análisis sociopolítico en tres niveles", en Revista de Psicología Social, vol.4, núm.2, 2009, pp.197-216; DE LA CORTE, L. “Qué sabemos y que ignoramos sobre la radicalización yihadista?”, en ANTÓN MELLADO (Ed.), Islamismo yihadista: radicalización y contrarradicalización, Valencia, Tirant lo Blanch, 2015; GARCÍA-CAVO, C. \& REINARES, F. "Radicalización yihadista y asociación diferencial: un estudio cuantitativo del caso español", en BERMEJO CASADO, R. \& BAZAGA FERNÁNDEZ, I. Radicalización violenta en España. Detección, gestión y respuesta (pp.29-42), Valencia, Tirant lo Blanch, 2019.

3 Sobre esta cuestión, DE LA CORTE advierte que el interés que ha suscitado en los últimos años el estudio de los procesos de radicalización también estaría motivado por el giro preventivo que han impulsado la inmensa mayoría de políticas y estrategias antiterroristas (DE LA CORTE, L., “QQué sabemos y que ignoramos sobre la radicalización yihadista?”, en ANTÓN MELLADO (Ed.), Islamismo yihadista: radicalización y contrarradicalización, Valencia, Tirant lo Blanch, 2015. Para el caso español, sirva como ejemplo el Plan Estratégico Nacional de Lucha contra la Radicalización Violenta. 
En este contexto donde el concepto de radicalización se ha tornado hegemónico, las prisiones, por su parte, han recibido una atención creciente al ser consideradas por una gran parte de la literatura especializada como espacios aptos para el acometimiento de tales procesos ${ }^{4}$, lo que ha generado una importante preocupación y la consiguiente implementación de medidas e instrumentos orientados a prevenir su aparición y neutralizar sus efectos ${ }^{5}$. En lo que se refiere de forma específica al sistema penitenciario español, la respuesta efectuada se ha articulado fundamentalmente en torno a dos Instrucciones de la Secretaria General de Instituciones Penitenciarias -Instrucción SGPI 8/2014 e Instrucción SGPI

4 En otras muchas, véase, CUTHBERTSON, I. M. "Prisons and the Education of Terrorist". en World Policy Journal, núm.3, 2004, pp.15-22; CILLUFO, F. y SAATHOFF, G. "Out of the Shadows. Getting ahead of prisoner radicalization", en The George Washington Homeland Security Policy Institute, Special Report, 2006, pp.1- 38; SILKE, A. "Terrorist, extremist and prison: an introduction to the critical issues", en SILKE, A. (ed.), Prisons, Terrorism and Extremism. Critical Issues in Management, Radicalisation and Reform, Londres, Routledge, 2014; RUSHCHENKO, J. "Terrorist recruitment and prison radicalization: Assessing the UK experiment of separation centres”, en European Journal of Criminology, Special Issue: Understanding European Jihadist: criminal, extremist or both, 2019, pp.1-20; NISTAL BURÓN, J. "Radicalización en prisión", en BERMEJO CASADO, R. y BAZAGA FERNÁNDEZ, I. Radicalización violenta en España. Detección, gestión y respuesta (pp.121-131), Valencia, Tirant lo Blanch, 2019.

5 En estos términos, por ejemplo, una de las cuestiones que más se ha debatido reside en el hecho de plantear si, para prevenir y neutralizar este fenómeno, son más efectivas las prácticas basadas en la dispersión de los presos ya radicalizados o, por el contrario, su concentración en un único establecimiento penitenciario. Para una revisión de las políticas llevadas a cabo en diferentes países, véase, NEUMANN, P. "Prisons and Terrorism. Radicalisation and De-radicalisation in 15 Countries", The International Centre for the study of radicalisation and political violence, 2010 y RUSHCHENKO, J. "Terrorist recruitment and prison radicalization: Assessing the UK experiment of separation centres", en European Journal of Criminology, Special Issue: Understanding European Jihadist: criminal, extremist or both, 2019, pp.1-20. 
2/2016 - y la Orden de Servicios 3/2018 de esta misma institución, estando esta última dirigida a desarrollar un instrumento para medir el riesgo de radicalismo violento en prisión.

Precisamente, el objetivo fundamental de este trabajo es examinar esta última orden de servicios desde una aproximación crítica. Para ello, con carácter previo, se abordan en primer lugar la radicalización como fenómeno social y las causas que explican por qué este fenómeno adquiere una especial relevancia en el contexto carcelario. Posteriormente, es analizado de forma específica el instrumento para medir el riesgo de radicalismo violento en prisión que introduce la Orden de Servicios 3/2018 como parte integrante de la respuesta que el sistema penitenciario español ha ofrecido ante el fenómeno de la radicalización islamista en las prisiones. Por último, se realizan toda una serie de consideraciones críticas sobre la naturaleza del mismo, poniéndose en evidencia que la figura del radical resultante, además de ser una pura construcción social, presenta importantes deficiencias que se traducen en una clara criminalización del pensamiento y la adopción de una política basada en la neutralización de la peligrosidad que, lejos de prevenir la radicalización, no hace sino potenciar las causas que alimentan su existencia.

6 Mientras que la Instrucción SGIP 8/2014 está más orientada hacia el control y la seguridad, la Instrucción SGIP 2/2016 queda inmersa en el plano tratamental de los sujetos ya radicalizados. En este sentido, véase, NISTAL BURÓN, J. "Radicalización en prisión”, en BERMEJO CASADO, R. y BAZAGA FERNÁNDEZ, I. Radicalización violenta en España. Detección, gestión y respuesta (pp.121-131), Valencia, Tirant lo Blanch, 2019. Para una análisis crítico sobre las mismas, véase por todos, ACALE SÁNCHEZ, M. "Terrorismo y tratamiento punitivista: más allá de la prisión”, en PÉREZ CEPEDA (Dir.), El terrorismo en la actualidad: un nuevo enfoque político criminal (pp.435-465), Valencia, Tirant lo Blanch, 2018; y CAROU GARCÍA, S.: "Yihadismo y Derecho Penitenciario: la prevención del extremismo violento en prisión desde una perspectiva tratamental", en Anuario de Derecho Penal y Ciencias Penales, núm.72, 2019, pp.521-566. 


\section{La radicalización como fenómeno social: una aproxima- ción a las causas que explican su relevancia en el ámbito pe- nitenciario}

Como han señalado Antón-Mellón y $\mathrm{Parra}^{7}$, entre otros $^{8}$, los intentos de definir la radicalización en términos absolutos han revelado constantes conflictos al tratar de establecer la relación entre radicalismo y violencia, y entre pensamiento y acción, lo que ha venido a dificultar notablemente el establecimiento de políticas funcionales exitosas. Sin embargo, es posible situarse junto con un amplio sector de la literatura académica y definir, de forma muy amplia, la radicalización islamista como un proceso por el cual ciudadanos residentes en un país occidental pasan a pertenecer $-\mathrm{O}$ a apoyar- a organizaciones yihadistas ${ }^{9}$. Mientras que, de un lado, ciertos autores ligan la radicalización islamista con sentimientos de injusticia y con la existencia de crisis identitarias ${ }^{10}$, otros, por su parte, relacionan este proceso con las

7 ANTÓN-MELLÓN, J.A. Y PARRA, I. "El concepto de radicalización”, en Cálamo. Revista de Estudios Jurídicos, núm. 1, 2014, pp: 75-90.

8 Sobre la confusión generada en torno al concepto, véase SEDGWICK, M. "The concept of radicalisation as a source of confusion", en Terrorism and Political Violence, núm. 22(4), 2010, pp: 479-494. Y para una revisión más amplia sobre el debate en torno a este concepto remitimos a: MANDEL, D.R. "Radicalisation: What does it mean?", en T.M. PICK et al. eds., Home-grown terrorism: Understanding and addressing the root causes of radicalization (pp. 101-112), Amsterdam, IOS Press, 2009; y a SCHMID, A.P., Radicalisation, De-Radicalisation, Counter-Radicalisation: A Conceptual Discussion and Literature Review, The Hague, ICCT, 2013.

9 KING, M., \& TAYLOR, D. M. "The Radicalization of Homegrown Jihadists: A Review of Theoretical Models and Social Psychological Evidence", en Terrorism and Political Violence, núm. 4(23), 2011, pp: 602-622.

10 Véanse: BORUM, R. "Understanding the Terrorist Mindset", en FBI Law Enforcement Bulletin, July, 2003, pp. 7-10; WIKTOROWIC, Q. "Joining the Cause: Al-Muhajiroun and Radical Islam", en The Roots of Islamic Radicalism Conference, Yale University, 2003; MOGHADDAM, F. M. "The Staircase to Terrorism: A Psychological Exploration", en American Psychologist, núm.60(2), 2005, pp.161-169; SILBER, M. D., 
estructuras sociales objetivas y la existencia de conflictos políticos ${ }^{11}$. Sin embargo, ambas posturas pueden ser entendidas como complementarias si tenemos en cuenta que este "proceso" opera en términos de una resignificación identitaria, por lo que, como tal, se articulará tanto en torno a representaciones subjetivas de la realidad como sobre las estructuras sociales que habita el sujeto ${ }^{12}$.

Entre la extensa bibliografía relativa a este tema, King y Taylor ${ }^{13}$ identificaron y destacaron cinco modelos teóricos dominantes para explicar la radicalización islamista: Borum's Pathway ${ }^{14}$, Wiktorowicz's Theory of Joining Extremist Groups ${ }^{15}$, Moghaddam's Staircase to Terrorism ${ }^{16}$, The

\& BHATT, A. Radicalization in the West: The Homegrown Threat", New York: NYPD Intelligence Division, 2007; SAGEMAN, M. "A Strategy for Fighting International Islamist Terrorists", en Annals of the American Academy of Political and Social Science, múm.618(1), 2008, pp.223-231; KING, M., \& TAYLOR, D. M. "The Radicalization of Homegrown Jihadists: A Review of Theoretical Models and Social Psychological Evidence", en Terrorism and Political Violence, núm.4(23), 2011, pp.602-622.

11 Véanse: BRENNAN-GALVIN, E. "Crime and Violence in an Urbanizing World”, en Journal of International Affairs, núm.56(1), 2002, pp.123145; HORGAN, J. The psychology of terrorism, London, Routledge, 2005; DE LA CORTE, L. \& JORDÁN ENAMORADO, J. La yihad terrorista, Madrid, Síntesis, 2007; JORDÁN ENAMORADO, J. "Procesos de radicalización yihadista en España. Análisis sociopolítico en tres niveles", en Revista de Psicología Social, vol.4, 2009, pp.197-216.

12 AGUERRI, J. C. "La doble dimensión de la radicalización islamista: el discurso de "los radicales islamistas" en las sentencias judiciales españolas", en Encrucijadas, núm. 16, 2018, pp.1-22

13 KING, M., \& TAYLOR, D. M. "The Radicalization of Homegrown Jihadists: A Review of Theoretical Models and Social Psychological Evidence", en Terrorism and Political Violence, núm. 4(23), 2011, pp: 602-622.

14 BORUM, R. "Understanding the Terrorist Mindset", en FBI Law Enforcement Bulletin, July, 2003, pp. 7-10.

15 WIKTOROWIC, Q. "Joining the Cause: Al-Muhajiroun and Radical Islam”, en The Roots of Islamic Radicalism Conference, 2003, Yale University. 
NYPD's Radicalization Process ${ }^{17}$ y Sageman's Four Prongs ${ }^{18}$.

En estos términos, los cinco modelos plantean una serie de etapas o factores diferentes que llevan a determinados individuos a la legitimación -en los planteamientos de Borum, Wiktorowicz y Sageman- o a la participación en un grupo o acto terrorista - en las posturas de Moghaddam y del NYPD-. Sin embargo, más allá las diferencias ${ }^{19}$, estos modelos tienen dos puntos clave en común: la privación relativa y las crisis de identidad ${ }^{20}$. En este sentido, de manera explícita o implícita, todos ellos hacen referencia tanto a la concurrencia de sentimientos de injusticia respecto a las condiciones materiales propias - $\mathrm{O}$ del grupo al que se pertenece ${ }^{21}$ - como a la existencia en los individuos radicalizados de una suerte de crisis de identidad que se zanja abrazando al Islam, el cual dota de una fe y de un estilo de vida íntimamente ligado con la política ${ }^{22}$.

16 MOGHADDAM, F. M. "The Staircase to Terrorism: A Psychological Exploration”, en American Psychologist, núm. 60(2), 2005, pp.161-169.

17 SILBER, M. D., \& BHATT, A. Radicalization in the West: The Homegrown Threat", New York, NYPD Intelligence Division, 2007.

18 SAGEMAN, M. "A Strategy for Fighting International Islamist Terrorists", en Annals of the American Academy of Political and Social Science, núm. 618(1), 2008, pp.223-231.

19 Fundamentalmente, KING Y TAYLOR destacan dos discrepancias clave en lo que se refiere al rol que se les atribuye a las organizaciones extremistas durante el proceso de radicalización y al papel que desempeñan las características de los individuos en este proceso. Véase, KING, M., \& TAYLOR, D. M. "The Radicalization of Homegrown Jihadists: A Review of Theoretical Models and Social Psychological Evidence", en Terrorism and Political Violence, núm. 4(23), 2011, pp: 602-622

20 KING, M., \& TAYLOR, D. M. "The Radicalization of Homegrown Jihadists: A Review of Theoretical Models and Social Psychological Evidence", en Terrorism and Political Violence, núm.4(23), 2011, pp.602622.

21 Entiéndase por grupo de pertenencia el grupo con el cual el sujeto se identifica subjetivamente.

22 ALY, W. Liquid Terror: The Dynamics of Homegrown Radicalisation, Sydney, Lowy Institute for International Policy, 2007. 
Como muestra el trabajo realizado por Mauger $^{23}$ en Francia, y como confirman los datos de los que disponemos para España ${ }^{24}$-por citar dos ejemplos lo más cercanos posibles-, la radicalización islamista es un fenómeno que envuelve mayoritariamente a jóvenes con nacionalidad europea (principalmente hijos de "inmigrantes"), residentes en áreas urbanas, con trayectorias vitales marcadas por la precariedad económica y los encuentros con el sistema penal ${ }^{25}$. Por tanto, como nos recuerda Mauger ${ }^{26}$, no podemos desligar la radicalización islamista de las transformaciones y dinámicas que han sacudido el espacio social de los estados occidentales en las últimas décadas. Como consecuencia de las mismas, las regiones dominadas del espacio social han quedado fuertemente fragmentadas, tanto de forma objetiva como subjetiva, y simbólicamente estigmatizadas ${ }^{27}$. Esto, por su parte, ha provocado que las crisis ideológicas e identitarias que viven las sociedades occidentales ${ }^{28}$ sean especialmente

23 MAUGER, G. ““Jeunes de cités”. Délinquance, émeutes et radicalisation islamiste", en Tempo Social, revista de sociología da USP, núm. 28(2), 2016, pp.39-56.

24 Véanse: REINARES, F., \& GARCÍA-CALVO, C. Estado Islámico en España, Madrid, Real Instituto Elcano, 2016; y REINARES, F., \& GARCÍA-CALVO, C. Yihadismo y yihadistas en España. Quince años después del 11-M, Madrid, Real Instituto Elcano, 2019.

25 Sobre esta cuestión, resulta especialmente esclarecedor el estudio efectuado por BASRA y sus colaboradores sobre 79 yihadista europeos con un pasado delictivo. Véase, BASRA, R., NEUMANN, P.R, BRUNNER, C.: "Criminal Pasts, Terrorist Future: European Jihadist and the New Crime-Terror Nexus", The International Centre for the study of radicalisation and political violence, 2016, pp. 1-54.

26 MAUGER, G. "“Jeunes de cités”. Délinquance, émeutes et radicalisation islamiste", en Tempo Social, revista de sociología da USP, núm. 28(2), pp: 39-56.

27 PEREIRA, V. B., SLATER, T., \& WACQUANT, L. "Territorial Stigmatization in action", en Environment and Planing A, núm. 46, 2014

28 Para una conceptualización detalla de los términos ideología e identidad, así como para un descripción de esta crisis, véase: DUBAR, C. La crisis de las identidades: la interpretación de una mutación, Barcelona, Bellaterrra, 2002, pp.12 y ss. 
duras en ciertos sectores. Por ejemplo, este sería el caso de la población "inmigrante" o de "ascendencia inmigrante" 29 .

En estos contextos ${ }^{30} \mathrm{y}$ siguiendo el análisis realizado en Francia por Mauger ${ }^{31}$, cierta interpretación del Islam se manifiesta para determinados jóvenes como una estrategia de revalorización simbólica que les permite lidiar con la anomia $^{32}$ a la que son sometidos. Ahora bien, como nos recuerda Sageman $^{33}$, esto no nos puede llevar a ligar de forma simplista unas condiciones de existencia objetivas con la radicalización

29 CANO PAÑOS, M. Á. "Relación de las Jornadas sobre Terrorismo Yihadista: Riesgos, Análisis y Respuestas. Universidad Miguel Hernández (Elche), 4 y 5 de mayo de 2016”, en Revista Electrónica de Ciencia Penal y Criminología, núm. 18-rl, 2016, pp.1-29.

30 A este respecto resulta ilustrativo recordar que una parte de la población española asocia a los inmigrantes con distintos problemas sociales -como "la delincuencia, la inseguridad, la integración o el choque culturar" (NOGUER SALANAS, S. "La sociedad de acogida: retos para una convivencia normalizada", en D. GÓMEZ-QUINTERO, Y C. MARCUELLO SERVÓS (eds.), Las políticas públicas y sociales en la encrucijada: incertidumbre, complejidad y cambio. Zaragoza, Universidad de Zaragoza, 2014, p.204). La memoria de 2016 del Ministerio Fiscal recoge que en España se observa "un progresivo crecimiento de los hechos denunciados y cometidos por intolerancia religiosa, siendo la mayoría casos de islamofobia". A estos factores se les suma la creciente racialización de la pobreza a la que asistimos desde la crisis de 2008, observada, entre otros, por: MARÍ-KLOSE, P. y MARÍ-KLOSE, M. “QQuién se empobrece y a quién estamos dispuestos a socorrer? Vulnerabilidad y solidaridad en un país en crisis", en II Jornadas aragonesas de sociología, Zaragoza, Prensas Universitarias, 2014; y LLANO ORTIZ, J. C. El estado de la pobreza: seguimiento del indicador de riesgo de pobreza y exclusión social en españa 2008-2011, Madrid, EAPN-ES, 2017

31 MAUGER, G. “"Jeunes de cités”. Délinquance, émeutes et radicalisation islamiste", en Tempo Social, revista de sociología da USP, núm. 28(2), 2016, pp,39-56.

32 Junto con MAUGER, utilizamos aquí el concepto de anomia empleado por MERTON, R. K. "Social Structure and Anomie", en American Sociological Review, núm.3(5), 1939, pp.672-682.

33 SAGEMAN, M., Understanding terrorist networks, Pennsylvania, University of Pennsyvania Press, 2004. 
puesto que, en síntesis, esta no es sino un proceso de movilización política. En este sentido, la evidencia empírica muestra que las personas pueden soportar altos niveles de discriminación antes de pasar a movilizarse ${ }^{34}$. Del mismo modo, también sugiere que son los activistas, las personas más concienciadas, los que perciben como más graves las violencias que recaen sobre el grupo con el que se identifican ${ }^{35}$.

Además, como argumentan Krueges y Malekováa ${ }^{36}$, el terrorismo es un fenómeno que, al orbitar en torno a un discurso y tener una fuerte carga ideológica, supone una incursión en el terreno de lo político ${ }^{37}$. En este sentido, como demuestran distintos estudios sobre movilización social ${ }^{38}$, esta requiere que el grupo que se moviliza se signifique a sí

34 Véase: WRIGHT, S. C., TAYLOR, D. M., \& MOGHADDAM, F. M. "Responding to Membership in a Disadvantaged Group: From Acceptance to Collective Protest", en Journal of Personality and Social Psychology, núm.58(6), 1990, pp.994-1003.

35 GOODWIN, J., JASPER, J. M., \& POLLETTA, F. Passionate Politics: Emotions and Social Movements, Chicago, University of Chicago Press, 2011.

36 KRUEGES, A. B., \& MALECKOVÁ, J. "Education, Poverty and Terrorism: is there a causal connection?", en Journal of Economic Perspectives, núm.17(4), 2003, pp.119-144.

37 En este mismo sentido se pronuncian DE LA CORTE, L., KRUGLANSKI, A., DE MIGUEL, J., SABUCEDO, J. M., \& DÍAZ, D. "Siete principios psicosociales para entender el terrorismo" en Psicothema, núm.19(3), 2007, pp.367 y ss.

38 Nos referimos aquí a estudios sobre movilización social no necesariamente vinculada al terrorismo. No obstante, dado lo expuesto, es necesaria su mención pues la movilización violenta comparte parte de sus características con cualquier tipo de movilización. A este respecto consideramos necesario citar los siguientes estudios: KLANDERMANS, B., DE WEERD, M. S., \& COSTA, M. "Injustice and adversarial frames in a supranational political context: Farmer's portesta in The Netherlands and Spain". En H. KRIESI, D. DELLA PORTA, \& D. RUCHT (Eds.), Social movements in a globalizing world (pp.173-197), Londres, McMillan, 1990, pp.180 y ss.; SABUCEDO, J. M., KLANDERMANS, B., RODRÍGUEZ, M., \& FERNÁNDEZ, C. "Identidad social, valoración política y movilización colectiva en un contexto supranacional”, en Revista de Psicología social, núm.15(3), 2000, pp.241-368. 
mismo de alguna forma, que comparta unas representaciones de sí mismo y de aquello que queda fuera. Estas creencias compartidas que conforman la identidad del grupo, por su parte, también enmarcan al adversario, al tiempo que legitiman las acciones llevadas a cabo para lograr los objetivos $\operatorname{marcados}^{39}$.

Si bien la identidad puede jugar diferentes papeles y no tiene porqué conducir a la movilización, los procesos de identidad social son una condición necesaria para la acción política $^{40}$, especialmente para el ejercicio de la violencia política. En este sentido, la identidad es resultado de procesos sociales de carácter dinámico y temporal, por lo que se desarrollan en un contexto y a través de relaciones ${ }^{41}$. A su vez, como desarrolló Denzin ${ }^{42}$, la identidad y las acciones que lleven a cabo los agentes sociales estarán influidas por las dinámicas e interacciones propias del conflicto, por lo que el intercambio de etiquetas y la conducta de la otra parte influirá en la forma que tomen las acciones.

En consecuencia, dadas las coordenadas expuestas, debemos entender que la radicalización islamista es un proceso social por el cual un individuo se sumerge en un conflicto político con unas características determinadas en el que,

39 Sobre una definición concreta de los mecanismos por los que los significados intercambiados en un conflicto configuran las formas de acción remitimos a los principios del interaccionismo simbólico desarrollados por BLUMER, H. El interaccionismo simbólico: perspectiva y método, Barcelona, Hora, 1982.

40 BARRETO, I., BORJA, H., SERRANO, Y., \& LOPEZ-LOPEZ, W. "La legitimación como proceso en la violencia política, medios de comunicación y construcción de culturas de paz", en Universitas Psychologica, núm.8(3), 2009, pp.737-748.

41 A este respecto véase: DEL OLMO VICÉN, N. "Construcción de identidades colectivas entre inmigrantes: ¿interés, reconocimiento y/o refugio?" en Reis: Revista española de investigaciones sociológicas, núm. 104, 2003, pp.29-56.

42 DENZIN, N. K. Symbolic Interactionism and Cultural Studies: The Politics of Interpretation, Oxford, Blackwell, 1992. 
como parte de un proceso de resignificación, se adscribe a una identidad que le significa como parte de un "nosotros". Es, por tanto, un proceso netamente ideológico que incumbe mayoritariamente a la moral y a la representación del individuo sobre el mundo.

Tomando como referencia este marco interpretativo, no resulta sorprendente que, atendiendo a sus condiciones estructurales, las prisiones hayan sido visualizadas por la literatura especializada como lugares aptos para el desarrollo de estos procesos ${ }^{43}$. Al fin y al cabo, estas no harían sino constituirse como «espacios de vulnerabilidad» donde la necesidad de redefinir la identidad personal se torna mucho más intensa ${ }^{44}$. No solo porque la persona es privada del contacto diario con su círculo cercano y enfrentada a su pasado sino sobre todo porque, al configurarse las prisiones como «instituciones totales $\rangle^{45}$, los individuos tienen que desarrollar toda una serie de estrategias adaptativas que resultan necesarias

43 Ahora bien, esto no significa que las prisiones se constituyan como el espacio de radicalización por excelencia. En este sentido, en lo que se refiere de forma específica al caso español, REINARES y sus colaboradores esgrimen que, de los yihadistas muertos o condenados en España desde 1996 hasta octubre de 2018, solo 1 de cada 10 se radicalizó parcial o totalmente cuando se encontraba recluido en un centro penitenciario. En este sentido, los domicilios privados, los lugares de culto y los espacios al aire libre arrojaron porcentajes superiores. Sobre esta cuestión, véase, REINARES, F., GARCÍA-CALVO, C. y VICENTE, A. Yihadismo y yihadistas en España. Quince años después del 11-M, Madrid, Real Instituto Elcano, 2019.

44 BASRA, R., NEUMANN, P.R, BRUNNER, C.: "Criminal Pasts, Terrorist Future: European Jihadist and the New Crime-Terror Nexus", The International Centre for the study of radicalisation and political violence, 2016, p.31.

45 Es decir, siguiendo a GOFFMAN, una «institución total» puede definirse como "un lugar de residencia y trabajo, donde un gran número de individuos en igual situación, asilados de la sociedad por un periodo apreciable de tiempo, comparten en su encierro una rutina diaria, administrada formalmente" (GOFFMAN, E. Internados. Ensayos sobre la situación social de los enfermos mentales, Buenos Aires, Amorrortu, 2001, p.13). 
para vivir en un medio caracterizado por su naturaleza excluyente, hostil y anormalizadora ${ }^{46}$.

En estos términos, siguiendo a Neumann ${ }^{47}$, la primera motivación que puede conducir a los internos a asumir e interiorizar una versión radical del Islam no es otra que esta necesidad de buscar significado y redefinir la identidad personal. Es decir, la «apertura cognitiva» que supone la entrada en prisión puede propiciar que, entre otras estrategias adaptativas, estos busquen respuestas espirituales a su situación personal y, en consecuencia, adopten o se adhieran con mayor énfasis a una postura religiosa ${ }^{48}$. En este sentido, convie-

46 Como consecuencia del encarcelamiento, LIEBLING y MARUNA han advertido que, entre otras, las personas privadas de libertad experimentan toda una serie de consecuencias somáticas y psicosociales que abarcan desde la ansiedad y el miedo a la soledad, pasando por experimentar sentimientos de injusticia, odio e incertidumbre (LIEBLING, A. y MARUNA, S. "Introduction: the effects of imprisonment revisited", en Alison LIEBLING y Shadd MARUNA (eds.), The Effects of Imprisonment, Nueva York, Routledge, 2006, p.3. Para un mayor detalle sobre el tipo de consecuencias -tanto somáticas como psicosocialesque experimentan las personas presas, véase, entre otras, VALVERDE MOLINA, J. La cárcel y sus consecuencias: la intervención sobre la conducta desadaptada, Madrid, Editoral Popular, 1999; RÍOS MARTÍN, J.C. Mil voces presas, Madrid, Universidad Pontificia de Comillas, 2001; CABRERA P.J, GALLEGO DÍAZ, M., SEGOVIA BERNABÉ, J. L., y RÍOS MARTÍN, J.C. Andar $1 \mathrm{~km}$ en línea recta. La cárcel del siglo XXI que vive el preso, Madrid, Universidad Pontificia de Comillas, 2010.

47 NEUMANN, P. "Prisons and Terrorism. Radicalisation and De-radicalisation in 15 Countries", en The International Centre for the study of radicalisation and political violence, $2010, \mathrm{pp} .28 \mathrm{y}$ ss.

48 En este sentido, en el universo definido por la realidad carcelaria, la religión no solo posibilita que las personas trasladen el control de sus propias vidas desde el sistema penitenciario hacia una entidad mucho más abstracta como es Dios o Ala, sino que, al mismo tiempo, esta permite que el encarcelamiento sea visualizado como una suerte de designio divino y una oportunidad para redimirse del pasado. En pocas palabras, la religión no haría sino ofrecer un sentimiento de seguridad y certeza que resulta enormemente valioso en el ámbito carcelario. Sobre esta cuestión, véase especialmente, MARRANCI, G. Faith, Ideology and Fear. Muslim Identities Within and Beyond Prisons, Londres, New York 
ne señalar que, durante las últimas décadas, la religión que más ha crecido en prisión ha sido precisamente el Islam $^{49}$.

Ahora bien, resulta necesario hacer una clara distinción entre el fenómeno de la conversión religiosa y la radicalización islamista. Mientras que la primera es relativamente frecuente y una opción totalmente lícita ${ }^{50}$, la segunda es una

Continuum, 2011, p. 69; y NEUMANN, P. y ROGERS, B. "Recruitment and Mobilisation for the Islamist Militant Movement in Europe", en European Commission, 2007, p.40.

49 En el caso de Estados Unidos, por ejemplo, se estima que, de aquellos internos que buscan respuestas en la religión, el $80 \%$ lo hace en el Islam, calculándose que aproximadamente se convierten a esta religión 35.000 internos cada años. Véase, HAMM, M. "Prison Islam in the age of sacred terror", en British Journal of Criminology, núm.49, 2009, p.669. Sobre las causas que explican este rápido crecimiento del Islam en detrimento de otras religiones, NEUMANN y ROGERS advierten que, mientras que algunos autores han conferido una especial importancia a las facilidades que conlleva la práctica de esta religión -por ejemplo, cualquier persona puede declararse a sí misma como musulmana sin la necesidad de que intervenga ninguna autoridad religiosa-, otros han centrado su explicación en la posición de desafío que representa la adopción del Islam ante la autoridad penitenciaria (NEUMANN, P. y ROGERS, B. "Recruitment and Mobilisation for the Islamist Militant Movment in Europe", en European Commission, 2007, p.40)

50 A pesar de que algunos autores han advertido que este crecimiento del Islam representa un riesgo que puede ser aprovechado por los grupos y las organizaciones terroristas, la evidencia empírica disponible sugiere que la adopción de esta religión desempeña un papel importante en la seguridad de los centros penitenciarios y la rehabilitación de los internos. En este sentido, entre otros muchos, véase, CLEAR, T. R., y SUMTER, M. T. "Prisoners, Prison and Religion", en Journal of Offender Rehabilitation, núm.35, 2002, pp.125-156; O'CONNOR, T. P. y PERREYCLEAR, M. "Prison religion in Action and its influence on offender rehabilitation", en Journal of Offender Rehabilitation, núm.35, 2002, pp.11-23; DIX-RICHARDSON, F. y CLOSE, B. R. "Religion, the Community, and the Rehabilitation of Criminal Offenders", en Journal of Offender Rehabilitation, núm.35, 2002, p.87-106; AMMAR, N.H., WEAVER, R. R. y SAXON, S. "Muslim in Prison: a case study from Ohio State Prisons", en International Journal of Offender Therapy and Comparative Criminology, núm.4, 2004, pp.414-428; SPALEK, B. y EL-HASSAN, S. "Muslim Converts in Prison", The Howard Journal, 
práctica mucho más limitada en sí misma ${ }^{51}$. De este modo, no tiene ningún sentido considerar $-\mathrm{y}$, por extensión, también criminalizar- la conversión religiosa como un indicio de radicalización. Esto, por su parte, no solo supondría una injerencia injustificada en la libertad religiosa del interno, sino que, además, contribuiría a alimentar la retórica victimista en la que se basan muchos de estos grupos ${ }^{52}$. Es decir, no se estaría sino trasladando la imagen de un Estado que, efectivamente, persigue y criminaliza al Islam. Por el contrario, el problema reside cuando, ante esta necesidad de redefinir la identidad personal, el recluso busca respuestas en corrientes religiosas que, más allá de la radicalidad de sus premisas, justifican el uso de la violencia como un medio legítimo para la consecución de objetivos políticos ${ }^{53}$.

Por otra parte, esta redefinición de la identidad personal a través de la asunción de una versión radical y belicosa del Islam también se puede ver favorecida por la propia naturaleza hostil de la prisión. En este sentido, es importante considerar que la violencia es un elemento consustancial a la vida carcelaria ${ }^{54}$, siendo esta especialmente acusada contra las minorías o las personas que se encuentran en una situación de especial vulnerabilidad ${ }^{55}$. Por ello, ante la necesidad de

núm.2, 2007, pp.99-114. Es decir, según advierte HAMM, más que un factor de riesgo, la adopción del Islam podría constituirse como un factor de protección frente a estos procesos (HAMM, M. "Prison Islam in the age of sacred terror", en British Journal of Criminology, n.49, 2009, p.669).

51 SILKE, A. y VELDHUIS, T. "Countering Violent Extremism in Prisons: a review of key recent research and critical research gaps", en Perspectives on Terrorism, núm.5, 2017, p.3

52 NEUMANN, P. "Prisons and Terrorism. Radicalisation and De-radicalisation in 15 Countries", The International Centre for the study of radicalisation and political violence, 2010, p..32.

53 HAMM, M. "Prison Islam in the age of sacred terror", en British Journal of Criminology, n.49, 2009, p.669.

54 RÍOS MARTÍN, J. C. Cuestiones de Política Criminal. Funciones y miserias del sistema penal, Granada, Comares, 2017, p. 102

55 MARRANCI, G. Faith, Ideology and Fear. Muslims identities within and beyond Prisons, Londres, Continuum International Publishing Group, 2011, p.67. 
protección y, por supuesto, también para evitar el aislamiento, una estrategia adaptativa puede consistir en unirse a grupos que, especialmente por afinidad cultural, ofrezcan una cierta sensación de seguridad y pertenencia ${ }^{56}$. Según sostienen Trujillo y sus colaboradores, esta formación de grupos étnicos cerrados representa un riesgo en sí mismo ya que esta situación podría ser aprovechada por los grupos terroristas para captar nuevos adeptos que, una vez se sientan más seguros e integrados, sean más volubles ante la comunicación persuasiva $^{57}$.

Por último, en el contexto de la prisión, también es importante advertir que la asunción de ciertas ideologías se presenta como un medio más para explicitar el rechazo que muchos internos sienten hacia la Administración Penitenciaria y, en una dimensión más general, hacia una sociedad que se considera injusta en sí misma ${ }^{58}$. En estos estos términos, los sentimientos de odio, enfado y desafección son perennes entre la población penitenciaria, lo que motiva la aparición de diferentes respuestas que, de una forma u otra, buscan hacer palpable este rechazo ${ }^{59}$. Aquí, precisamente, algunos autores sitúan las causas que explican el rápido crecimiento

56 Sobre esta cuestión, BRANDON señala algunos ejemplos en los que internos islamistas radicales en las cárceles británicas se aproximaban a recién llegados bajo el pretexto de ofrecerles comida, apoyo espiritual o, simplemente, una amistad. Para un mayor detalle, véase, BRANDON, J. "The danger of prison radicalization in the West", en CTC SENTINEL, núm.2, 2009, pp.2 y ss.

57 TRUJILlO, H. M., JORDÁN, J. y GONZÁLEZ CABRERA, J. "Radicalization in prisons? Field research in 25 Spanish Prisons", en Terrorism and Political Violence, núm.2, 2009, p.559.

58 NEUMANN, P. "Prison and Terrorism. Radicalisation and Deradicalisation in 15 countries", The International Centre for the Study of Radicalisation and Political Violence, 2010, p.29

59 MULCAHY, E., MERRINGTON, S. y BELL, P. "The radicalisation of prison inmates. Exploring recruitment, religion and prisoner vulnerability", en Journal of Human Security, núm.1, 2013, p.7. 
del Islam en detrimento de otras religiones ${ }^{60}$. Al fin y al cabo, especialmente en lo que se refiere a las versiones más radicales, estas no harían sino constituirse en sí mismas como una negación frontal de la validez del sistema, presentándose como una suerte de desafío.

\section{La Orden de Servicios 3/2018 como parte de la respuesta del sistema penitenciario español frente al fenómeno de la radicalización islamita en prisión}

Por tanto, tal y como se ha podido apreciar en el apartado inmediatamente anterior, la radicalización es un proceso social que, debido a su propia naturaleza, encuentra en las prisiones un lugar apto para su desarrollo, lo que ha motivado que, por parte de los Estados, se implementen toda una serie de medidas e instrumentos orientados a prevenir su aparición y neutralizar sus efectos. En este sentido, aunque existen iniciativas previas ${ }^{61}$, la respuesta que ofrece actualmente el sistema penitenciario español ante este fenómeno se articula en torno a dos Instrucciones de la Secretaría General de Instituciones Penitenciarias -Instrucción SGIP 8/2014 e Instrucción SGIP 2/2016- y la Orden de Servicios 3/2018 de esta misma institución.

A pesar de que este artículo tiene por objeto examinar únicamente esta última Orden de Servicios, resulta necesario realizar, aunque sea brevemente, un comentario sobre la

60 NEUMANN Y ROGERS, citando a KHOSROKHAVAR, advierten que, especialmente en Francia, el islam representa hoy lo que fue el marxismo años atrás (NEUMANN, P. R. y ROGERS, B. "Recruitment and Mobilisation for the Islamist Militant Movment in Europe", en European Commission, 2007, p. 40

61 Sobre esta cuestión, véase especialmente, MARTÍNEZ MARTÍNEZ, M. A. "Estrategias contra el terrorismo islamista en prisión", en ALONSO RIMO, A., CUERDA ARNAU, M. A. Y FERNÁNDEZ HERNÁNDEZ, A., (Dir.), Terrorismo, sistema penal y derechos fundamentales, Valencia, Tirant lo Blanch, 2018. 
Instrucción 8/2014 y la Instrucción 2/2016, ya que entre ellas se complementan mutuamente y conforman una respuesta conjunta ante el fenómeno de la radicalización islamista en las prisiones:

En relación con la primera, denominada como "Nuevo Programa para la prevención de la radicalización yihadista en los centros penitenciarios", se advierte en el propio texto que tiene como principal finalidad limitar la presencia de este fenómeno en los centros penitenciarios. Para ello, se especifica que, primordialmente, se trata de recoger, analizar y sistematizar todo un conjunto de datos que permitan detectar y acotar los procesos de radicalización incipientes o ya consolidados. En este sentido, la Instrucción 8/2014 divide a los internos susceptibles de verse involucrados en este proceso - tanto de forma activa como pasiva- en tres grupos diferenciados: por una parte, el Grupo A engloba a aquellos internos que han sido condenados por pertenencia o colaboración con organización terrorista. Por otra parte, en el Grupo B son clasificados aquellos reclusos que, enmarcados en una actitud de liderazgo captador y proselitista, realizan labores de captación y difusión de ideas radicales entre el resto de la población penitenciaria. Por último, el Grupo C incluiría a aquellas personas que, debido a su situación personal, son más vulnerables ante el proceso de radicalización.

La consecuencia inmediata de ser clasificado en alguno de estos grupos, por su parte, sería la inclusión en alguno de los Ficheros de Internos de Especial Seguimiento (FIES) existentes ${ }^{62}$. Además, también se especifican otras cuestiones,

62 A pesar de que la Instrucción 8/2014 excluye de este tratamiento en un primer momento al Grupo C, esta decisión es modificada posteriormente por la Instrucción $2 / 2015$, donde se establece que este grupo será incluido en el FIES 5 "Características Especiales". Por otra parte, conviene advertir que ser incluido en un FIES no es una cuestión de menor importancia ya que estos llevan aparejados toda una serie de medidas de seguridad y control que limitan enormemente la vida carcelaria. Para una lectura crítica sobre tales ficheros, véase, BRANDARIZ GARCÍA, 
entra ellas que la coordinación de este Plan recae sobre el Subdirector de Seguridad y que, cuando exista un alto nivel de certeza de que el recluso presenta un elevada peligrosidad, no resultará prudente la concesión de permisos de salida, la clasificación en tercer grado o el acceso a la libertad condicional.

Por otra parte, la Instrucción SGIP 2/2016, denominada como "Programa Marco de intervención en radicalización violenta con internos islamistas", complementa la anterior al desarrollar un programa de tratamiento que está dirigido a intervenir con sujetos ya radicalizados. En este este sentido, se parte de reconocer que, incluso en estos supuestos, la reeducación y la reinserción social son dos fines que deben guiar la actividad de la Administración Penitenciaria. De este modo, se señala que la finalidad de este programa no es otra que ayudar a estos internos a que superen los planteamientos que robustecen su ideología totalitaria, además de constituirse en sí mismo como una clara apuesta por la defensa social ${ }^{63}$.

J. A. "Notas sobre el régimen cerrado para penados considerados extraordinariamente peligrosos. Departamentos Especiales y F.I.E.S (CD)", en Estudios Penales y Criminológicos, núm.23, 2002, pp.7-58; RÍOS MARTÍN, J. C. Manual de ejecución penitenciaria: defenderse en la cárcel, Madrid, Colex 2014; CAROU GARCÍA, S. Primer grado penitenciario y Estado de Derecho: el estatus jurídico de los reclusos en régimen de máxima seguridad, Barcelona, Bosch, 2017; GONZÁLEZ COLLANTES, T. "Prisión y Terrorismo Yihadista: los FIES como medida penitenciaria de prevención de atentados, de adiestramiento y reclutamiento con fines terroristas", en ALONSO RIMO, A., CUERDA ARNAU, M. A. Y FERNÁNDEZ HERNÁNDEZ, A., (Dir.)., Terrorismo, sistema penal y derechos fundamentales, Tirant lo Blanch, Valencia, 2018.

63 Esta referencia a la defensa social, por su parte, ha sido criticada desde un sector de la literatura especializada al entender que no resulta oportuna en una instrucción específicamente contextualizada en el ámbito tratamental. En este sentido, esta referencia ha sido tomada como una muestra más de la dimensión securitaria del tratamiento que se está ofreciendo. Para un mayor detalle, véase, ACALE SÁNCHEZ, M. "Terrorismo y tratamiento punitivista: más allá de la prisión”, en PÉREZ 
En estos términos, los destinatarios del programa serían los tres grupos establecidos en la instrucción anterior, señalándose toda una serie de pautas específicas ${ }^{64}$ y comunes de tratamiento. En relación con estas últimas, por ejemplo, se advierte que se promoverá una interpretación del Islam moderada que esté alejada de cualquier perspectiva extremista ${ }^{65}$ y que, en todo caso, se facilitará el aprendizaje del español, la mejora del nivel educativo y la integración sociocultural.

CEPEDA (Dir.), El terrorismo en la actualidad: un nuevo enfoque politico criminal (pp.435-465), Valencia, Tirant lo Blanch, 2018; y CAROU GARCÍA, S. "Yihadismo y Derecho Penitenciario: la prevención del extremismo violento en prisión desde una perspectiva tratamental", en Anuario de Derecho Penal y Ciencias Penales, núm.72, pp.521-566.

64 Como actuación específica con el Grupo A, se prevé una intervención individual, intensa y duradera en el tiempo que, entre otras cuestiones, busqué la mejora en la capacidad empática del interno, su formación en los valores y principios propios de un Estado de Derecho y, en última instancia, el abordaje y la modificación de aquellos aspectos actitudinales que los han llevado a justificar y/o cometer un acto de terrorismo. Por el contrario, con los Grupos B y C se plantea un tratamiento conjunto que descanse sobre la identificación de aquellas variables psicosociales que podrían explicar el origen, el mantenimiento y la consolidación de los procesos de radicalización violenta. Además, con estos grupos, también se podrá contar la ayuda de internos de apoyo musulmanes. Asimismo, como líneas de actuación específicas con los Grupos B y C, se señala que, en todo caso, se procurará una mejora en la capacidad empática y autoestima de estos internos, el fomento de su autonomía personal y, en última instancia, la superación de las actitudes extremistas que los han llevado a justificar la violencia.

65 Para ello, se advierte que se contará con la ayuda de imanes moderados al amparo del Convenio existente entre la Secretaria General de Instituciones Penitenciarias y la Federación Islámica. El hecho de promocionar una determinada interpretación religiosa y no otra, por su parte, ha sido visto por CAROU como una cuestión problemática ya que esto podría llegar a suponer una intromisión en la libertad religiosa que, en ningún caso, se encuentra amparada por el ordenamiento jurídico. Véase, CAROU GARCÍA, S.: "Yihadismo y Derecho Penitenciario: la prevención del extremismo violento en prisión desde una perspectiva tratamental", en Anuario de Derecho Penal y Ciencias Penales, núm.72, 2019, pp.558 y ss. 
Por último, a través de la Orden de Servicios 3/2018, la Secretaria General de Instituciones Penitenciarias ha creado un instrumento de evaluación para medir el riesgo de radicalismo violento en prisión ${ }^{66}$. A pesar de que la citada orden hace referencia expresa a que este instrumento "de ningún modo puede considerarse un predictor estático de la conducta futura", su objetivo general es "la detección y valoración de variables que pueden indicar un riesgo real de comisión de actos relacionados con el radicalismo violento". A su vez, sus objetivos específicos son: "ayudar en la toma de decisiones en lo relativo al tratamiento penitenciario", "servir de instrumento de coordinación entre los distintos departamentos penitenciarios" y "sistematizar el tratamiento sobre el radicalismo violento llevado a cabo en los distintos centros penitenciaros".

66 Este tipo de instrumentos para medir el riesgo, por su parte, no son novedosos puesto que, desde la emergencia de la denominada «sociedad del riesgo», han surgido en todos los ámbitos de conocimiento diferentes herramientas que, guardando una elevada similitud con las prácticas desarrolladas por las compañías aseguradoras, han buscado gestionar y predecir los riesgos. La Política Criminal, en estos términos, no ha permanecido ajena a esta tendencia, produciéndose toda una penetración de las lógicas actuariales en los sistemas penales y penitenciarios contemporáneos. Sobre esta cuestión, véase especialmente, HARCOURT, B. Against Prediction. Profiling, Policing, and Punishing in Actuarial Age, Chicago, The University of Chicago, 2007; y O'MALLEY, P. Crime and Risk, Londres, Sage Publications, 2010. Para un análisis específico del caso Español, remitimos a RIVERA BEIRAS, I. "Actuarialismo Penitenciario. Su recepción en España”, en Revista Crítica Penal y Poder, núm.9, 2015, pp.102-144; y BRANDARÍZ GARCÍA, J. A. El modelo gerencial-actuarial de penalidad. Eficiencia, riesgo y sistema penal, Madrid, Dykinson, 2016. En lo que se refiere de forma específica al terrorismo y la medición del riesgo de radicalización, se han desarrollado instrumentos como el ERG22 y el VERA. Para una revisión sobre el uso de los mismos y las variables que los componen, véase, HERZOG-EVANS, M. "A comparision of two structured judgment tools for violent extremism and their relevance in the French context", en European Journal of Probation, núm.1, pp.3-27; LOGAN, C. y LLOYD, M. "Violent extremism: a comparison of approaches to assessing and managing risk", en Legal and Criminological Psychology, núm.24, 2018, pp.141-161. 
Según advierte la Orden de Servicios 3/2018, todo el personal de la Administración Penitenciaria debe convertirse en "agente activo" para la implementación del instrumento ${ }^{67}$, siendo el Equipo Técnico de la prisión el encargado de cumplimentarlo y de analizarlo, utilizándose para ello la información obtenida de la observación directa del interno y de su evolución en los programas de tratamiento o intervención en los que participe. Los reclusos a los que el instrumento se destina son todos aquellos incluidos en los Grupos A, B y $\mathrm{C}$, a los cuales se les aplicará el instrumento una vez sean incluidos en estos grupos, repitiéndose la evaluación cada seis meses. Además, también podrá aplicársele a cualquier otro interno del que se haya informado para su posible inclusión en alguno de estos grupos.

Para conseguir los objetivos establecidos, el instrumento parte de la necesidad de incidir sobre tres variables para evitar futuros comportamientos delictivos: "el riesgo", entendido como la probabilidad de reincidencia; la "necesidad", que tiene en cuenta los factores que han motivado directamente el acto delictivo; y la "responsividad", es decir, "la respuesta del sujeto hacia determinados estilos de intervención". En base a estos criterios, el "Instrumento de evaluación del riesgo de radicalismo violento" se ha construido buscando ser una herramienta que, en función de su evolución, vaya asignando a los internos un determinado nivel de riesgo alto, medio o bajo.

Para asignar estos niveles de riesgo, el Instrumento plantea un total de 39 factores de carácter cualitativo, para cuyo estudio ofrece unas pautas que permiten codificarlos en función de su presencia baja, media o elevada. La informa-

67 Se hacen reiteradas referencias en la Orden de Servicios 3/2028 a la necesidad de que todo el personal se convierta en "agente activo", insistiéndose especialmente en la necesidad de colaboración y coordinación de los agentes de las áreas de tratamiento y de los funcionarios del área de seguridad. 
ción necesaria para evaluar el grado de presencia de estos factores se extraerá de la observación del interno, de sesiones individualizadas con él y del estudio documental de su expediente. Estos 39 factores se dividen en tres categorías: "Factores A de riesgo de violencia radical" (tabla 1), que hacen referencia a una "elevada radicalización" y a una supuesta "intencionalidad violenta"; y "Factores B-C de riesgo de proselitismo-captación y radicalización personal" (tabla 2), entre los que se encuentran factores relativos al "afán" captador del interno -Factores B-, así como aquellos indiciarios de procesos de radicalización -Factores $\mathrm{C}-$.

\begin{tabular}{|c|l|}
\hline \multicolumn{2}{|c|}{ Tabla 1 } \\
\hline A1 & Tendencia a la conducta violenta \\
\hline A2 & $\begin{array}{l}\text { Antecedentes de violencia relacionada específicamente con el } \\
\text { extremismo }\end{array}$ \\
\hline A3 & Medio social externo vinculado al radicalismo violento \\
\hline A4 & Intención de cometer actos en defensa de su ideología \\
\hline A5 & Identificación de un objetivo al que atacar \\
\hline A6 & Impulsividad conductual \\
\hline A7 & Rasgos psicopáticos \\
\hline A8 & Trastorno mental grave \\
\hline A9 & Justificación y afinidad con colectivos violentos \\
\hline A10 & Reciente entrenamiento físico \\
\hline A11 & Resistencia al cumplimiento de la normativa del centro \\
\hline A12 & Presencia o intervención de material extremista \\
\hline & Fuente: elaboración propia a partir de la Orden de Servicios 3/2018 \\
\hline
\end{tabular}

\section{Tabla 2}

Factores B-C de riesgo de proselitismo-captación y radicalización violenta

\begin{tabular}{|l|l|l|l|}
\hline $\mathrm{BC} 1$ & $\begin{array}{l}\text { Necesidad de orientar a } \\
\text { otros internos sobre la } \\
\text { práctica religiosa }\end{array}$ & $\mathrm{BC} 15$ & $\begin{array}{l}\text { Repetición de hábitos y } \\
\text { conductas diarias }\end{array}$ \\
\hline
\end{tabular}




\begin{tabular}{|c|c|c|c|}
\hline $\mathrm{BC} 2$ & $\begin{array}{l}\text { Necesidad de mayor } \\
\text { status personal }\end{array}$ & $\mathrm{BC} 16$ & $\begin{array}{l}\text { No participación en } \\
\text { actividades }\end{array}$ \\
\hline $\mathrm{BC} 3$ & $\begin{array}{l}\text { Tendencia a la organiza- } \\
\text { ción colectiva de actos } \\
\text { religiosos }\end{array}$ & $\mathrm{BC} 17$ & $\begin{array}{l}\text { Ausencia de planes de } \\
\text { futuro }\end{array}$ \\
\hline $\mathrm{BC} 4$ & $\begin{array}{l}\text { No se tolera la existencia } \\
\text { de árabes no creyentes }\end{array}$ & BC18 & $\begin{array}{l}\text { Constancia de conver- } \\
\text { sión religiosa (en prisión } \\
\text { o en otro lugar) }\end{array}$ \\
\hline $\mathrm{BC} 5$ & $\begin{array}{l}\text { Presta apoyo a otros } \\
\text { internos }\end{array}$ & BC19 & $\begin{array}{l}\text { Sentimientos de indife- } \\
\text { rencia hacia las víctima } \\
\text { de actos violentos de } \\
\text { tipo extremista }\end{array}$ \\
\hline BC6 & $\begin{array}{l}\text { Sentimiento de debilidad } \\
\text { y/o vulnerabilidad per- } \\
\text { sonal }\end{array}$ & $\mathrm{BC} 20$ & $\begin{array}{l}\text { Existencia de una pobre } \\
\text { autoestima }\end{array}$ \\
\hline $\mathrm{BC} 7$ & $\begin{array}{l}\text { Sentimientos de agravio } \\
\text { personal y/o trato injusto }\end{array}$ & $\mathrm{BC} 21$ & $\begin{array}{l}\text { El interno se muestra } \\
\text { influenciable }\end{array}$ \\
\hline $\mathrm{BC} 8$ & $\begin{array}{l}\text { Sentimientos de ataque al } \\
\text { grupo que siente propio }\end{array}$ & $\mathrm{BC} 22$ & $\begin{array}{l}\text { Existencia de cambios } \\
\text { recientes en su rutina } \\
\text { diaria }\end{array}$ \\
\hline BC9 & $\begin{array}{l}\text { Relaciones preferentes } \\
\text { con musulmanes }\end{array}$ & $\mathrm{BC} 23$ & $\begin{array}{l}\text { Persistencia conductual } \\
\text { pese al etiquetamiento } \\
\text { normativo }\end{array}$ \\
\hline $\mathrm{BC} 10$ & $\begin{array}{l}\text { Percepción de categorías } \\
\text { sociales diferenciadas } \\
\text { ("nosotros"y "vosotros") }\end{array}$ & $\mathrm{BC} 24$ & $\begin{array}{l}\text { Movimientos de sepa- } \\
\text { ración interior modular } \\
\text { y/o celular }\end{array}$ \\
\hline $\mathrm{BC} 11$ & $\begin{array}{l}\text { Sentimientos de rechazo } \\
\text { a los funcionarios y a la } \\
\text { institución }\end{array}$ & $\mathrm{BC} 25$ & $\begin{array}{l}\text { La religión es el pilar de } \\
\text { su identidad y la inter- } \\
\text { pretación dominante }\end{array}$ \\
\hline $\mathrm{BC} 12$ & $\begin{array}{l}\text { Rechazo a los funciona- } \\
\text { rios y al personal feme- } \\
\text { nino }\end{array}$ & $\mathrm{BC} 26$ & $\begin{array}{l}\text { Dificultad para admitir } \\
\text { otras interpretaciones de } \\
\text { la realidad }\end{array}$ \\
\hline $\mathrm{BC} 13$ & $\begin{array}{l}\text { Rechazo del tratamiento } \\
\text { y no percepción de la } \\
\text { necesidad de cambio } \\
\text { personal }\end{array}$ & $\mathrm{BC} 27$ & $\begin{array}{l}\text { Necesidades personales } \\
\text { básicas no cubiertas }\end{array}$ \\
\hline $\mathrm{BC} 14$ & Tendencia al aislamiento & \multicolumn{2}{|c|}{$\begin{array}{l}\text { Fuente: elaboración propia a par- } \\
\text { tir de la Orden de Servicios } 3 / 2018\end{array}$} \\
\hline
\end{tabular}

Por último, el resultado final tras la aplicación de este instrumento es una valoración del riesgo global que, en todo 
caso, debe ser necesariamente tenida en cuenta en la toma de decisiones por parte de los órganos colegiados.

\section{Aproximación crítica a la Orden de Servicios 3/2018}

De este modo, como se puede apreciar, la Orden de Servicios 3/2018 introduce un instrumento para evaluar el riesgo de radicalismo violento en prisión. En este sentido, resulta ahora pertinente realizar toda una serie de consideraciones críticas sobre la naturaleza del mismo y las consecuencias que comporta su existencia.

\section{a. La construcción del radical}

En primer lugar, es importante advertir que, a pesar de estar revestidos de una aura de objetividad y cientifici$\mathrm{dad}^{68}$, los instrumentos basados en la gestión del riesgo no dejan de ser puras construcciones culturales. Es decir, como señala Brandariz sobre esta cuestión, "el riesgo y su activación en clave de control social son construcciones colectivas, preñadas de elementos culturales, morales y políticos"69. En este sentido, el hecho de ser etiquetado como un radical, lejos de ser el producto de una mera operación matemática ${ }^{70}$, no haría sino reflejar la concatenación de toda una serie de valoraciones subjetivas que se extienden desde el momento en el que se constituyen los diferentes factores hasta que estos se evalúan y se presentan los resultados.

68 DE GIORGI, A. El gobierno de la excedencia. Postfordismo y control de la multitud, Madrid, Traficantes de Sueños, 2006, p.131.

69 BRANDARIZ GARCÍA, J. A. "La difusión de las lógicas actuariales y gerenciales en las políticas punitivas", en InDret. Revista para el Análisis del Derecho, núm.2, 2014, p.8.

70 Sobre esta cuestión es importante advertir que, a diferencia de otros, el instrumento contenido en la Orden de Servicios 3/2018 no presenta una naturaleza especialmente matemática ya que no se trata de una prueba baremada y estandarizada (NISTAL BURÓN, J.: "Radicalización en prisión”, en BERMEJO CASADO, R. y BAZAGA FERNÁNDEZ, I. Radicalización violenta en España. Detección, gestión y respuesta (pp.121-131), Valencia, Tirant lo Blanch, 2019, p.125. 
Este hecho, por su parte, lejos de resultar intrascendente, presenta una importancia decisiva para la temática aquí planteada puesto que, si se atiende a la naturaleza de las variables contenidas en este instrumento, rápidamente se advierte que la figura del radical resultante, además de ser una pura construcción social, presenta importantes deficiencias:

En este sentido, un primer punto que debe destacarse es que una parte sustancial de los Factores B-C hacen referencia a toda una serie de consecuencias psicosociales que, desde la literatura especializada ${ }^{71}$, han sido señaladas como producto del encarcelamiento. En estos términos, por ejemplo, se establece que, en relación con el factor BC6 -sentimientos de debilidad y/o vulnerabilidad personal-, se considerará que la persona presenta un riesgo alto cuando, entre otros aspectos, "carece de una red social protectora y/o experimenta sentimientos de miedo y/o ansiedad". Por otra parte, en el factor $\mathrm{BC} 11$-sentimientos de rechazo a los funcionaros y la Institución-, se establece que el riesgo es medio cuando el interno realiza "comentarios ocasionales despectivos o negativos hacia la prisión y los funcionarios". Asimismo, en el factor $\mathrm{BC} 17$-ausencia de planes de futuro-, se entiende que el riesgo es alto cuando el interno no tiene ningún plan de futuro y no dispone de una red sociofamiliar de apoyo. Por su parte, en el factor BC20 - existencia de una pobre autoestima-, se señala que el riesgo será alto cuando "el interno se

71 Véase, entre otras, SYKES, G. The society of captives: A Study of maximum security prison, Princeton, Princeton University Press, 2007; VALVERDE MOLINA, J. La cárcel y sus consecuencias: la intervención sobre la conducta desadaptada, Madrid, Editoral Popular, 1999; RÍOS MARTÍN, J.C., Mil voces presas, Madrid, Universidad Pontificia de Comillas, 2001; LIEBLING, A. y MARUNA, S. "Introduction: the effects of imprisonment revisited", en Alison LIEBLING y Shadd MARUNA (eds.), The Effects of Imprisonment, Nueva York, Routledge 2006; CABRERA P.J, GALLEGO DÍAZ, M., SEGOVIA BERNABÉ, J. L.,RÍOS MARTÍN, J.C. Andar $1 \mathrm{~km}$ en línea recta. La cárcel del siglo XXI que vive el preso, Madrid, Universidad Pontificia de Comillas, 2010. 
considera una persona débil, incapaz y sin apenas virtudes o capacidades personales" $"$.

Sobre esta cuestión, resulta importante advertir que, para una parte muy significativa de las personas presas, estos sentimientos de vulnerabilidad y/o rechazo y enfado son una constante en su trayectoria penitenciaria. En este sentido, este hecho nos lleva a suponer que, si tales factores fuesen evaluados por sí mismos entre la población penitenciaria general, la inmensa mayoría de internos obtendrían una puntuación alta de riesgo de radicalización ya que, en resumidas cuentas, la cárcel se configura como un ambiente anormalizador y excluyente que genera precisamente esta vulnerabilidad y sentimientos de rechazo. Sin embargo, evidentemente, no todos ellos son considerados como radicales, lo que sugiere que son el resto de factores contemplados los que ejercen una influencia decisiva en la asignación de esta etiqueta.

En este sentido, un elemento preocupante de la Orden de Servicios 3/2018 es que hace reiteradas referencias a cuestiones morales, ideológicas y religiosas en calidad de factores de riesgo de radicalización. En estos términos, muchos de los denominados "Factores de riesgo B-C de proselitismocaptación y radicalización personal", aunque también ciertos "Factores A de Riesgo de Violencia Radical"73, remiten a cuestiones internas de la persona. Por ejemplo, en el factor de riesgo $\mathrm{BC} 2$-necesidad de un mayor estatus personal-, en-

72 De nuevo, conviene advertir que, aunque aquí únicamente se han señalado cuatro factores que remiten directamente a las consecuencias psicosociales del internamiento, esta cuestión es una constante entre los Factores B-C. En este sentido, también cabe destacar: sentimientos de agravio personal y/o trato injusto $(\mathrm{BC} 7)$; rechazo del tratamiento y no percepción de necesidad de cambio personal (BC13); tendencia al aislamiento (BC14); repetición de hábitos y conductas diarias ( $\mathrm{BC} 15)$; no participación en actividades (BC16); el interno se muestra influenciable (B21); necesidades personales no cubiertas (BC27).

73 En este sentido, tanto el factor de riesgo A4 -intención de cometer actos en defensa de su ideología- como el factor A5 -identificación de un objetivo al que atacar hace referencia a cuestiones internas del sujeto. 
contramos como característica de riesgo alto que el interno tenga "inquietudes personales relacionadas con la defensa de la religión". Asimismo, en el factor $\mathrm{BC} 4$-no se tolera la existencia de árabes no creyentes-, se menciona como elemento que denotará un riesgo medio el que el interno considere que "sería apropiado hablar con esas personas y conocer los motivos de su no religiosidad". Por último, en lo que se refiere al factor de riesgo $\mathrm{BC} 19$-sentimientos de indiferencia hacia las víctimas de actos violentos de tipo extremista-, se especifica que denotará un riesgo alto el que no se verbalicen "comentarios de condolencia o lamento hacia ellas"74.

Asimismo, en referencia específica a los "Factores A de Riesgo de Violencia Radical", si bien es cierto que algunos de ellos guardan una mayor relación con el fenómeno de la radicalización violenta ${ }^{75}$, otros remiten a cuestiones que, al menos a primera vista, nada tienen que ver. En este sentido, en el Factor A8 -trastorno mental grave-, por ejemplo, se establece que se considerará un riesgo alto cuando exista un diagnóstico psiquiátrico que revele problemas de adaptación y de conducta, además de existir constancia de que la persona se está medicando. También, en una misma línea, el Factor A10 -reciente entrenamiento físico- establece como

74 A pesar de que aquí únicamente se han señalado en el cuerpo del trabajo tres factores que remiten a cuestiones morales y/o religiosas, estos son una constante a lo largo de los veintisiete Factores B-C. En este sentido, también cabe señalar: necesidad de orientar a otros internos sobre la práctica religiosa $(\mathrm{BC} 1)$; tendencia a la organización colectiva de actos religiosos (BC3); sentimientos de ataque el grupo que siente como propio (BC8); relaciones preferentes con musulmanes (BC9); percepción de categorías sociales diferencias (BC10); constancia de conversión religiosa (BC18); la religión es el pilar de su identidad y la interpretación dominante (BC25); dificultad para admitir otras interpretaciones de la realidad (BC26).

75 Aquí podrían ser situados los siguientes factores: tendencia a la conducta violenta (A1); antecedentes de violencia específicamente relacionada con el extremismo (A2); medio social externo vinculado con el radicalismo (A3); justificación y afinidad con colectivos violentos (A9); presencia o intervención de material extremista (A12). 
riesgo alto que "el interno dedica tiempo diariamente a la mejora física, habiéndose convertido este comportamiento en un hábito recurrente de inicio reciente" $" 76$.

De este modo, tal y como se puede apreciar, el instrumento contenido en la Orden de Servicios 3/2018 se compone de toda una serie de factores que, orbitando fundamentalmente en torno a cuestiones morales, ideológicas y religiosas, no parecen del todo apropiados, extendiéndose a extremos tan estrafalarios como si el interno ha realizado ejercicio físico recientemente o si tiene alguna patología mental. En este sentido, lejos de dar cuenta de una cualidad natural, el resultado obtenido tras la aplicación de este instrumento no sería sino la creación de una categoría social -el "radical" - cuyas bases más elementales se sustentan sobre la esfera interna del individuo, con todas las consecuencias que de ello se derivan.

\section{b. Sobre la criminalización del pensamiento y sus po- sibles efectos en la ejecución penitenciaria}

Ahora bien, a pesar de que la figura del radical resultante es una pura construcción social, esta genera toda una serie de consecuencias reales, convirtiéndose el riesgo en una suerte de estigma para quienes lo sufren ${ }^{77}$. De entrada, conviene recordar que este instrumento, por ejemplo, sirve para valorar la inclusión de internos en los Grupos A, B y C, lo que generaría importantes restricciones en la vida carcelaria. En este sentido, consideramos que, tal y como está planteado, este instrumento supone una clara intromisión en la esfera interna del individuo que, por su parte, contraviene frontalmente los principios limitadores de la intervención punitiva del Estado.

76 Dentro de estos Factor A que, aparentemente nada tienen que ver con el fenómeno de la radicalización, también pueden ser citados: impulsividad conductual (A6); rasgos psicopáticos (A7); resistencia al cumplimiento de la normativa del centro.

77 DEL ROSAL BLASCO, B. “Hacía un Derecho Penal de la postmodernidad? en Revista Electrónica de Ciencia Penal y Criminología, núm.11(08), 2009, p.28. 
En primer lugar, el hecho de realizar reiteradas referencias a cuestiones morales, ideológicas y religiosas nos parece especialmente preocupante puesto que tal instrumento podría llegar a suponer una clara criminalización del pensamiento. En este sentido, si los datos generados se tuvieran en cuenta para cuestiones como la concesión de permisos de salida o las progresiones de grado ${ }^{78}$, estaríamos hablando del establecimiento de sanciones encubiertas en atención a la moral e ideología del interno, lo que viola el artículo 3 LOGP y el artículo $16 \mathrm{CE}$. En este sentido, se estaría poniendo en juego una visión de los fines de la pena que daría la razón a las posturas más críticas con el artículo 25.2. $\mathrm{CE}^{79}$, ya que se estaría llevando el tratamiento penitenciario a la esfera moral del individuo, castigando a quienes no adopten una concreta visión del mundo, lo cual implica ir contra el sentido de nuestro texto constitucional y la tradición garantista que, en teoría, ha venido rigiendo la política penal española ${ }^{80}$.

El principio cogitationes poenam nemo patitur no es ajeno a nuestro ordenamiento pues ha sido incorporado por la doctrina, en calidad de principio limitador/configurador del ius puniendi, como principio de responsabilidad por el

78 Algo más que factible si se tiene en cuenta que la Orden de Servicios 3/2018 establece que "en la toma de acuerdos de los órganos colegiados de los internos FIES integrantes de los señalados grupos tendrá carácter preceptivo que sus miembros conozcan el Instrumento de evaluación de riesgo de radicalismo violento, que concluye aspectos de seguridad y tratamiento, para la deliberación y voto. A tal fin, se participará por el Secretario de los órganos colegiados copias del mismo con anterioridad a sus sesiones para conocimiento del Presidente y vocales participantes".

79 Para un estudio en profundidad sobre los debates que sucedieron a la inclusión del artículo 25.2 en la CE véanse: GARCÍA PABLOS, A. "La supuesta función resocializadora del Derecho penal: utopía, mito y eufemismo" en Anuario de derecho penal y ciencias penales, núm.32, 1979, p.645-700; y MUÑOZ CONDE, F. La resolución del delincuente: Análisis y Crítica de un mito. En S. MIR, La Reforma del Derecho Penal (pp.61-80). Barcelona, Bellaterra. 1980.

80 MELENDO PARDOS, M., CALLEJO GALLEGO, M. J., y LACRUZ LÓPEZ, J. M. Apuntes de Política Criminal, Madrid, Dykinson, 2019. 
$h e c h o^{81}$. Como explica Cancio Meliá, este "se entiende como aquel principio genuinamente liberal de acuerdo con el cual debe quedar excluida la responsabilidad jurídico-penal para meros pensamientos, es decir, como rechazo de un Derecho Penal orientado con base en la actitud interna del autor" $"$. Como continua el autor, este principio "cristaliza en la necesidad estructural de un hecho como contenido central del tipo (Derecho penal del hecho en lugar de Derecho penal de autor)" "83. No puede, por tanto, el derecho penal penar meros pensamientos ni meras ideas. Y, como ya hemos expuesto, tampoco puede el Derecho Penitenciario limitar ni castigar meros pensamientos o posturas ideológicas.

A pesar de este hecho, diversos autores han señalado que la aplicación de ciertos delitos para castigar conductas relacionadas con la radicalización tiende a violar este principio de responsabilidad penal por el hecho ${ }^{84}$. Delitos como

81 Véase: DÍEZ RIPOLLÉS, J. L. Derecho penal español. Parte General. Valencia, Tirant lo Blanch, 2016.

82 CANCIO MELIÁ, M. ¿Derecho Penal del Enemigo? En G. JAKOBS, \& M. CANCIO MELIÁ, Derecho Penal del Enemigo (pp. 57-103), Madrid, Civitas, 2003, p.101.

83 Ibíd. p.101.

84 Véanse: CANCIO MELIÁ, M. "Derecho penal del enemigo y delitos de terrorismo. Algunas consideraciones sobre la regulación de las infracciones en materia de terrorismo en el Código penal español después de la LO 7/2000", en Jueces para la Democracia, núm.44, 2002, pp.19-26; RAMOS VÁZQUEZ, J. A. "Presente y futuro del delito de enaltecimiento y justificación del terrorismo", en Anuario da Facultade de Dereito da Univeridade da Coruña, núm.12, 2008, pp.771-793; CANCIO MELIÁ, M. Los delitos de terrorismo: estructura típica e injusto. Madrid, Reus. 2010; CANO PAÑOS, M. Á. "La reforma penal de los delitos de terrorismo en el año 2015: Cinco cuestiones fundamentales", en Revista General de Derecho Penal, núm.23, 2015; GALÁN MUÑOZ, A. “¿Leyes que matan ideas frente a las ideas que matan personas? Problemas de la nueva represión de los mecanismos de captación terrorista tras la reforma del código penal de la LO 2/2015", en Revista de Derecho Penal y Criminología, núm.15, 2015, pp.95-138; CANO PAÑOS, M. Á. "La nueva amenaza terrorista y sus (negativas) repercusiones en el ordenamiento penal y constitucional. Comentario 
el enaltecimiento del terrorismo, la difusión del terrorismo o el autoadoctrinamiento penan como delitos de terrorismo conductas cuya única relación con este fenómeno delictivo (sus acciones o sus organizaciones) es meramente subjetiva ${ }^{85}$. Es decir, como señala Cano Paños ${ }^{86}$, la única relación entre las conductas típicas y cualquier otro delito de terrorismo existe únicamente en la mente del sujeto. En estos delitos, el elemento central del tipo es ese elemento subjetivo, la finalidad que, en teoría, dota de peligrosidad a la conducta. Ahora bien, como dicha peligrosidad no pude observarse en la conducta, esta ha de predicarse de las características del sujeto.

La Orden de Servicio 3/2018 prolonga esta lógica y la introduce en el ámbito penitenciario, construyendo una herramienta que, mediante una serie de factores, busca y construye la peligrosidad de ciertos sujetos. En este sentido, a través del instrumento analizado, se continua la construcción político-jurídica del radical, otorgándole una existencia que, en todo caso, vendría especialmente marcada por la presencia de unas ideas que no son tolerables y de las que se deriva esencialmente su peligrosidad. En este contexto, no es baladí que su construcción se realice en base a factores de riesgo que remiten a su moral, ideología o religión, ya que así se

a la Sentencia de la Audiencia Nacional núm. 39/2016, de 30 de noviembre", en Revista de Derecho Constitucional Europeo núm.27, 2017, pp.1-44; CANCIO MELIÁ, M. y DÍAZ LÓPEZ, J. A. ¿Dircurso del odio y/o discurso terrorista? Pamplona, Aranzadi, 2019; CARRASCO ANDRINO, M. "Derechos fundamentales y legislación antiterrorista: ¿qué hemos perdido en el camino?”, en Estudios Penales y Criminológicos, vol.XXXIX, 2019, pp. 59-105.

85 AGUERRI, J. C. "La construcción del radical como enemigo en el Código Penal español: los elementos de los delitos aplicados para gestionar la radicalización islamista y sus implicaciones para el Estado de Derecho", en Revista Electrónica de Ciencia Penal y Criminología, núm.21, 2019, pp.1-26.

86 CANO PAÑOS, M. Á. "La reforma penal de los delitos de terrorismo en el año 2015: Cinco cuestiones fundamentales", en Revista General de Derecho Penal, núm.23, 2015 
desliga la existencia del radical de conductas externas y la peligrosidad se deriva exclusivamente de sus ideas, de su visión del mundo y su moral, es decir, de su posición ideológica. Queda así configurado el radical como un sujeto cuya "mera existencia supone un riesgo para el orden social" 87 . Es decir, queda construido como el enemigo necesario para justificar la puesta en juego de un Derecho Penal del Riesgo, como un sujeto cuya peligrosidad es tal que la necesidad de prevenir el mal que pueda causar prepondera sobre los principios más básicos del ordenamiento jurídico.

En estos términos, en lo que se refiere al campo específico de la ejecución penitenciaria, la Orden de Servicios 3/2018 -y, sobre todo, su forma de entender la radicalidadabre dos posibles líneas de actuación que, presentando serios problemas de constitucionalidad, se mueven entre la persecución de la reeducación y la reinserción social en un sentido amplio -esto es, como una forma de intervención sobre los valores, la ideología e incluso el pensamiento del individuoy la neutralización de la peligrosidad criminal mediante la inocuización de la persona. En este sentido, cabe recordar que, tal y como se ha advertido más arriba, el hecho de obtener una puntuación alta tras la aplicación de este instrumento no es una cuestión superflua puesto que la inclusión en los Grupos A, B y C determina, en otras cuestiones, la existencia de un tratamiento penitenciario específico y la implementación de toda una serie de medidas de control y seguridad adicionales.

En relación con la primera cuestión, el hecho de construir la figura del radical sobre aspectos puramente morales, ideológicos y religiosos abre la posibilidad de que la Administración Penitenciara, a través del tratamiento, tenga la tentación de incidir sobre los mismos. De hecho, esta posibilidad parece sugerirse cuando, a pesar de señalarse que se

87 RIVERA BEIRAS, I. Politica criminal y Sistema Penal: Viejas y nuevas racionalidades Punitivas. Barcelona, Anthropos y OSPDH, 2005, p.225. 
evitará la criminalización de prácticas religiosas perfectamente legítimas, la Instrucción SGIP 2/2016 dispone que, como elemento común de tratamiento, se promoverá en todo caso desde la Administración una visión no extremista del Islam, contándose para ello con la ayuda de imanes moderados al amparo del Convenio firmado entre la Secretaria General de Instituciones Penitenciarias y la Federación Islámica.

Ahora bien, cabe recordar que el mandato constitucional recogido en el art. 25.2 CE no es una carta blanca a la institución, por lo que, como han establecido doctrina, jurisprudencia y la propia legislación penitenciaria, el tratamiento penitenciario tiene ciertos límites, fuera de los cuales quedan, por supuesto, la moral, ideología y religiosidad del individuo ${ }^{88}$. En este sentido, a diferencia de otros países donde sí son posibles este tipo de intervenciones ${ }^{89}$, la finalidad del tratamiento en el sistema penitenciario español no pude ser otra que hacer del interno una persona capaz de vivir respetando la ley penal y subvenir a sus propias necesidades, lo que excluye cualquier tipo de aspiración basada en la pretensión de modificar sus pensamientos o creencias.

Esta última pretensión, por su parte, sería plenamente incompatible con una sociedad pluralista y democrática ${ }^{90}$,

88 Como advierte SILVA SÁNCHEZ, en el contexto de una sociedad plural y democrática donde se reconoce el derecho a la dignidad y al libre desarrollo de la personalidad, esta posición supondría una injerencia injustificable (SILVA SÁNCHEZ, J. Aproximación al Derecho Penal contemporáneo, Barcelona, Bosch Editorial, 1992, p.30)

89 A diferencia de lo acaecido en la inmensa mayoría de los países occidentales, los programas de desradicalización que han implementado en algunos países de Oriente Medio y el Sudeste Asiático sí inciden directamente sobre aspectos ideológicos. Sobre esta cuestión, véase como ejemplo el llevado a cabo en Arabia Saudí: AL-HADLAQ, A. "Saudi Efforts in Counter-Radicalisation and Extremist Rehabilitation", en Gunaratna, R. y Bin Ali, M., Terrorist Rehabilitation. A new frontier in Counter-terrorism (pp.21-39), London, Imperial College Press, 2015.

90 En este sentido se prenuncia LAMARCA PÉREZ, C. "Régimen penitenciario y derechos fundamentales", en Estudios Penales y Criminológicos, núm. XVI, 1993, pp.210-247. 
y mucho menos con una democracia no militante como la que impera en España. En este sentido se ha manifestado el Tribunal Constitucional en diversas ocasiones ${ }^{91}$, sosteniendo una postura que puede sintetizarse en que la Constitución "es un marco de coincidencias suficientemente amplio como para que dentro de él quepan opciones políticas de muy distinto signo" $" 92$ que "protege también a quienes la niegan"93. Además, tal y como establece el propio art. 25.2 CE, el penado gozará de todos sus derechos fundamentales a excepción de los que se vean expresamente limitados por el contenido del fallo condenatorio, el sentido de la pena y la ley penitenciaria. En este sentido, resulta poco discutible que estos factores limitadores no pueden afectar en ningún caso a la libertad ideológica y religiosa protegida por el art. $16 \mathrm{CE}$, más allá del impedimento de acudir a ciertos lugares de culto y otras limitaciones derivadas de la privación de libertad. De hecho, debe recordarse que la propia LOGP establece en su artículo 3 que la actividad penitenciaria se ejercerá respetando "la personalidad humana de los recluidos y los derechos e intereses jurídicos de los mismos no afectados por la condena", añadiendo en el mismo artículo que esta labor se llevará a cabo "sin establecerse diferencia alguna por razón de raza, opiniones políticas, creencias religiosas, condición social o cualesquiera otras circunstancias de análoga naturaleza”.

De este modo, a pesar de tratarse de una relación de sujeción especial, la Administración Penitenciaria no está en ningún modo habilitada para realizar este tipo de intervenciones que inciden sobre la libertad ideológica y religiosa del interno ${ }^{94}$. Ahora bien, al margen de esta forma de entender la reeducación y la reinserción social -que, tal y como se ha

91 Véanse la STC 48/2003, de 14 de marzo; la STC 174/2006, de 5 de junio; la STC 192/1980, de 8 de abril de 1981 y la STC 176/1995, de 11 de diciembre.

92 STC 192/1980, de 8 de abril de 1981

93 STC 176/1995, de 11 de diciembre. 
podido apreciar, es abiertamente inconstitucional-, otra vía de actuación preferente que podría derivarse de la naturaleza del instrumento analizado y que, a nuestro juicio, es la que finalmente ha seguido la Administración Penitenciaria, consiste en olvidarse de cualquier tipo de aspiración tratamental -extremo que, por su parte, también contraviene lo dispuesto en el art. 25.2 CE-y perseguir únicamente la neutralización de la citada peligrosidad a través de la inocuización e incapacitación del sujeto etiquetado como radical.

En este sentido, es importante advertir que, durante las últimas décadas, la política criminal española, al igual que la de los países de su entorno, ha tendido hacia la adopción de un modelo securitario en el que la prevención especial negativa parece haberse convertido en la principal función de la prisión ${ }^{95}$. En este contexto, es razonable considerar que la Orden de Servicios 3/2018 venga a convertirse en un instrumento destinado a detectar un supuesto riesgo de radicalización que, más que orientar un tipo de intervención tratamental como la expuesta más arriba, esté sobre todo dirigido a justificar la puesta en marcha de medidas tendentes a aislar al interno tanto del resto de presos como de la sociedad. Este camino, más allá de poder ser objeto de todas las

94 En este sentido, la jurisprudencia del Tribunal Constitucional es clara al señalar que las relaciones de especial sujeción "no se dan al margen del Derecho, sino dentro de él y por lo tanto también dentro de ellas tienen vigencia los derechos fundamentales" STC [pleno] 188/2005, de 4 de Julio. Además, Véanse las SSTC 2/1987, de 21 de enero; 42/1987, de 7 de abril; 61/1990, de marzo; y la STC [pleno] 188/2005, de 4 de julio. A este respecto cabe añadir, como hace la STC 58/1998, de 16 de marzo, que las relaciones de especial sujeción "deben ser entendidas en un sentido reductivo, compatible con el valor preferente de los derechos fundamentales".

95 FERNÁNDEZ ABAD, C. "La resignificación de la pena de prisión y su renovada funcionalidad en el contexto de la «sociedad excluyente»: aproximación crítica al desplazamiento del ideal resocializador desde una lógica estructural", Revista de Derecho penal y Criminología, núm.18, 2017, pp.217-263. 
críticas de las que es objeto el modelo securitario, debe ser especialmente censurado en el ámbito de la radicalización ya que puede causar el efecto contrario al deseado.

Cabe recordar, continuando con lo expuesto supra, que la adopción de ciertas interpretaciones yihadistas del Islam y la movilización en pos de ellas es un passage a l'acte que se produce no solo sobre la base de unas condiciones de existencia percibidas como injustas -recuérdese la ya comentada importancia de la privación relativa en los procesos de radicalización- sino que, en términos de McAdams y sus colaboradores ${ }^{96}$, tiene lugar en virtud de una forma concreta de verse a uno mismo y de ver el mundo, es decir, en nombre de una identidad. Esta identidad, que relaciona la experiencia individual y la colectiva ${ }^{97}$, se construye en torno a un nosotros y un ellos ${ }^{98}$, y está condicionada por los intercambios simbólicos propios del conflicto ${ }^{99}$.

Esta dinámica, propia de cualquier conflicto, es especialmente relevante en aquellos casos en los que está implicada

96 MCADAMS, TARROW Y TILLY desarrollan una interesante sociología del conflicto político que llama la atención sobre la importancia en los conflictos de los procesos de intercambio de significados entre las partes que en ellos participan. A este respecto véase: McADAMS, D., TARROW, S., y TILLY, C. Dinámicas de la contienda política, Barcelona, Hacer, 2005, pp.151 y ss.

97 Para una explicación detalla de la relación entre experiencia individual y colectiva en la construcción de identidad remitimos a: DELLA PORTA, D. y DIANI, P. Los movimientos sociales. Madrid, CIS y Editorial Complutense, 2011.

98 Como sostiene PARK (PARK, R. E. La ciudad y otros ensayos de ecología urbana, Barcelona, Serval, 2005, pp. 66 y ss.), entrar a formar parte de un nosotros permite compartir con otros unas representaciones y sentidos que generan una narración coherente sobre uno mismo. Sin embargo, no puede obviarse que, como también sostiene el autor, todo grupo se construye en oposición a una alteridad, por lo que estas "representaciones y sentidos" no vendrán solo del grupo, sino que también procederán del propio conflicto.

99 Seguimos aquí lo expuesto por: BLUMER, H. El interaccionismo simbólico: perspectiva y método, Barcelona, Hora, 1982. 
de algún modo la violencia política, ya que, como sostiene Ruggiero $^{100}$, cada una de las partes que ejerce la violencia lo hará justificándose en los excesos del otro y, a la vez, aceptando las definiciones con las que el contrario le significa, aceptando el rol de parte contraria amenazante ${ }^{101}$. Es decir, que esa resignificación identitaria no solo pasa por cierta interpretación del Islam, sino también por una serie de etiquetas procedentes del Estado que recaerán sobre el agente ${ }^{102}$.

El Estado no juega aquí exclusivamente el papel de institución que confronta el yihadismo, sino que, además, en nuestras sociedades, el Estado es el gran detentador de la violencia simbólica ${ }^{103}$, es decir, de la capacidad de imponer representaciones del mundo ${ }^{104}$. En este sentido, dichas representaciones influyen en el agente social incluso cuando las niega, pues obligan al agente a repensarlas y repensarse en unos términos que le son ajenos. De este modo, el Estado tiene la capacidad para crear y difundir categorías ${ }^{105}$ que ten-

100 RUGGIERO, V. La violencia política: un análsis criminológico, Barcelona, Anthropos, 2009, p.233.

101 Un ejemplo claro de la importancia de este intercambio de significados en el terrorismo yihadista es la noción de muyahidín que, pese a tener un origen religioso, es representado básicamente como un soldado occidental. Véase a este respecto: AGUERRI, J. C. "La doble dimensión de la radicalización islamista: el discurso de "los radicales islamistas" en las sentencias judiciales españolas”, en Encrucijadas, núm.16, 2018, pp.1-22.

102 RUGGIERO, V. La violencia política: un análisis criminológico. Barcelona, Anthropos, 2009, p.157.

103 Término acuñado y desarrollado por Pierre Bourdieu en, entre otras obras: BOURDIEU, P. "Classes sociales et pouvoir symbolique", en L'Arc, núm.72, 1978, pp.13-19.

104 Dicho en otros términos, la violencia simbólica es la capacidad "de hacer ver y de hacer creer, de confirmar o de transformar la visión del mundo". De este modo, la violencia simbólica se erige como el resultado de "el poder de imponer (ciertamente de inculcar) instrumentos de conocimiento y de expresión (taxonomías) arbitrarias (pero ignoradas como tales) de la realidad social" (BOURDIEU, P. Intelectuales, Política y Poder, Buenos Aires, UBA/Endeba, 2000, p.69.

105 Para una descripción precisa de los mecanismos a través de los que el Estado define lo real, así como del propio concepto y funcionamiento 
drán tanto una eficacia práctica -se plasman en políticas que inciden en lo real-como una eficacia simbólica -transmiten categorías que serán subjetivadas por los agentes sociales-.

Teniendo en cuenta estas cuestiones, debemos observar que, si bien el radical es una construcción social, es decir, no es posible encontrar en esta idea propiedades ontológicas que la definan ${ }^{106}$, el radical sí que existe cono producto de una serie de narrativas políticas que, en el caso que nos ocupa, se traducen en ciertas políticas penitenciarias que tienes consecuencias reales, especialmente en lo que se refiere tanto a la imposición de un endurecimiento del régimen de cumplimiento de la condena y la imposición de unas condiciones de aislamiento tendentes a inocuizar al sujeto como a la producción y difusión de una categoría -el radical- que, a la postre, es susceptible de ser incorporada por los propios agentes a los que se etiqueta de radicales.

En estos términos, ya sea por la vía de imponer ciertas condiciones de cumplimiento especialmente duras derivadas de la supuesta necesidad de inocuización del sujeto o por la vía del etiquetamiento, la aplicación de la Orden 3/2018 con la finalidad de neutralizar la supuesta peligrosidad del delincuente puede llegar a suponer la efectiva producción de un riesgo de radicalización, puesto que, al fin y al cabo, las

del Estado remitimos a: BOURDIEU, P. Sobre el Estado, Barcelona, Anagrama, 2014.

106 No desarrollar esta concepción del radical como constructo nos llevaría a hacernos preguntas irresolubles como: ¿cuándo una idea empieza a ser radical? ¿Cuál es la diferencia entre radical y moderado? ¿Es la radicalidad una propiedad inherente al sujeto o la ideas que asume? ¿Qué entendemos por asumir unas ideas? ¿La radicalidad es medible sincronía o diacrónicamente? Todas estas cuestiones nos remiten a la vieja problematización sobre los conceptos de normalidad y desviación, tan ampliamente trabajados por autores como: FOUCAULT, M. Los anormales, Barcelona, Akal, 2001; FOUCAULT, M. Hay que defender la sociedad, Barcelona, Akal, 2003; CANGUILHEM, G. Lo normal y lo patológico, México, Siglo XXI, 2005. 
políticas penitenciarias que lleva asociadas no hacen sino potenciar las causas que nutren la existencia de estos procesos.

\section{Conclusiones: ¿un instrumento para medir el riesgo de ra- dicalismo violento?}

Por tanto, tal y como se ha podido apreciar a lo largo del texto, la Orden de Servicios 3/2018 de Instituciones Penitenciarias introduce un instrumento que, lejos de medir el radicalismo violento, en la práctica no hace sino (re)producirlo y potenciarlo al estimular toda una serie de políticas basadas en la neutralización de la peligrosidad que favorecen la aparición de las causas principales que explican la radicalización islamista. Al fin y al cabo, si este proceso viene mediado fundamentalmente por la privación relativa y la resignificación identitaria, el endurecimiento de las condiciones de encarcelamiento y la asignación de la etiqueta del radical se constituyen como dos presupuestos básicos para alimentar su existencia.

En este sentido, nos parece especialmente preocupante que, bajo la lógica preventista -esto es, actuar ante una amenaza que todavía no es tal-, la figura del radical se construya a partir de factores que, siendo puramente subjetivos, inciden directamente sobre la moral, ideología y religiosidad del interno. Este hecho, por su parte, no solo supone una clara criminalización del pensamiento que contraviene frontalmente los principios limitadores de la intervención punitiva del Estado sino que, incluso desde una posición estrictamente pragmática que anteponga la búsqueda de eficacia a la protección de los derechos fundamentales, tampoco parece especialmente apropiado (re)producir una categoría que, pudiéndose volver real en sus consecuencias, termine por propiciar y consolidar la existencia de estos procesos.

Por todo ello, urge realizar una revisión profunda de este instrumento y, en una dimensión más general, de la 
respuesta que ha ofrecido el sistema penitenciario español ante el fenómeno de la radicalización islamista en las prisiones. Al fin y al cabo, la naturaleza estrictamente securitaria de la misma no solo compromete los derechos fundamentales sino que, en síntesis, tampoco resultar eficaz para prevenir y neutralizar la existencia del fenómeno abordado.

\section{Bibliografía}

ACALE SÁNCHEZ, M. "Terrorismo y tratamiento punitivista: más allá de la prisión", en PÉREZ CEPEDA (dir.), El terrorismo en la actualidad: un nuevo enfoque político criminal, Valencia, Tirant lo Blanch, 2018.

AGUERRI, J. C. "La doble dimensión de la radicalización islamista: el discurso de "los radicales islamistas" en las sentencias judiciales españolas”, en Encrucijadas, núm.16, 2018.

AGUERRI, J. C. "La construcción del radical como enemigo en el Código Penal español: los elementos de los delitos aplicados para gestionar la radicalización islamista y sus implicaciones para el Estado de Derecho", en Revista Electrónica de Ciencia Penal y Criminología, núm.21, 2019, pp. 1-26.

AL-HADLAQ, A. "Saudi Efforts in Counter-Radicalisation and Extremist Rehabilitation", en Gunaratna, R. y Bin Ali, M., Terrorist Rehabilitation. A new frontier in Counter-terrorism (pp.21-39), London, Imperial College Press, 2015. https://doi.org/10.1142/9781783267446_0002.

ALONSO PASCUAL, R. "Procesos de radicalización y reclutamiento en las redes de terrorismo yihadista", en Cuadernos de Estrategia, núm.141, pp. 21-68.

ALY, W. Liquid Terror: The Dynamics of Homegrown Radicalisation, Sydney, Lowy Institute for International Policy, 2007.

AMMAR, N.H., WEAVER, R. R. y SAXON, S. "Muslim in Prison: a case study from Ohio State Prisons", en 
International Journal of Offender Therapy and Comparative Criminology, núm.4, 2004, pp. 414-428.

ANTÓN-MELLÓN, J.A. y PARRA, I. "El concepto de radicalización", en Cálamo. Revista de Estudios Jurídicos, núm. 1, 2014, pp. 75-90.

BARRETO, I., BORJA, H., SERRANO, Y., y LOPEZ-LOPEZ, W., "La legitimación como proceso en la violencia política, medios de comunicación y construcción de culturas de paz", en Universitas Psychologica, núm.8(3), 2009, pp. 737-748.

BASRA, R., NEUMANN, P. R. y BRUNNER, C. "Criminal Pasts, Terrorist Future: European Jihadist and the New Crime-Terror Nexus", en The International Centre for the study of radicalisation and political violence, 2016, pp.1-54

BLUMER, H., El interaccionismo simbólico: perspectiva y método, Barcelona, Hora, 1982.

BORUM, R., "Understanding the Terrorist Mindset", en FBI Law Enforcement Bulletin, July, 2003, pp. 7-10.

BOURDIEU, P., "Classes sociales et pouvoir symbolique", en L'Arc, núm. 72, 1978, pp.13-19.

BOURDIEU, P., Intelectuales, Política y Poder, Buenos Aires, UBA/Endeba, 2000.

BOURDIEU, P., Sobre el Estado, Barcelona, Anagrama, 2014.

BRANDARIZ GARCÍA, J. A., "Notas sobre el régimen cerrado para penados considerados extraordinariamente peligrosos. Departamentos Especiales y F.I.E.S (CD)", en Estudios Penales y Criminológicos, núm. 23, 2002, pp. 7-58.

BRANDARIZ GARCÍA, J. A., "La difusión de las lógicas actuariales y gerenciales en las políticas punitivas", en InDret. Revista para el Análisis del Derecho, núm.2, 2014.

BRANDARIZ GARCÍA, J. A., El modelo gerencial-actuarial de penalidad. Eficiencia, riesgo y sistema penal, Dykinson, Madrid, 2016. 
BRANDON, J. "The danger of prison radicalization in the West", en CTC SENTINEL, núm. 2, 2009.

BRENNAN-GALVIN, E., "Crime and Violence in an Urbanizing World", en Journal of International Affairs, núm. 56 (1), 2002, pp. 123-145.

CABRERA P. J., GALLEGO DÍAZ, M., SEGOVIA BERNABÉ, J. L., y RÍOS MARTÍN, J.C., Andar $1 \mathrm{~km}$ en línea recta. La cárcel del siglo XXI que vive el preso, Madrid, Universidad Pontificia de Comillas, 2010.

CANCIO MELIÁ, M., "Derecho penal del enemigo y delitos de terrorismo. Algunas consideraciones sobre la regulación de las infracciones en materia de terrorismo en el Código penal español después de la LO 7/2000", en Jueces para la Democracia, núm. 44, 2002, pp. 19-26.

CANCIO MELIÁ, M., “¿Derecho Penal del Enemigo?”, en G. JAKOBS, y M. CANCIO MELIÁ, Derecho Penal del Enemigo, Madrid, Civitas, 2003.

CANCIO MELIÁ, M., Los delitos de terrorismo: estructura típica e injusto, Madrid, Reus, 2010.

CANCIO MELIÁ, M. y DÍAZ LÓPEZ, J. A., ¿Discurso del odio y/o discurso terrorista?, Pamplona, Aranzadi, 2019.

CANGUILHEM, G., Lo normal y lo patológico, México, Siglo XXI, 2005.

CANO PAÑOS, M. Á., "La reforma penal de los delitos de terrorismo en el año 2015: Cinco cuestiones fundamentales", en Revista General de Derecho Penal, núm. 23, 2015.

CANO PAÑOS, M. Á., "Relación de las Jornadas sobre Terrorismo Yihadista: Riesgos, Análisis y Respuestas. Universidad Miguel Hernández (Elche), 4 y 5 de mayo de 2016", en Revista Electrónica de Ciencia Penal y Criminología, núm.18, 2016, pp. 1-29.

CANO PAÑOS, M. Á., "La nueva amenaza terrorista y sus (negativas) repercusiones en el ordenamiento penal y constitucional. Comentario a la Sentencia de la Au- 
diencia Nacional núm. 39/2016, de 30 de noviembre", en Revista de Derecho Constitucional Europeo, núm.27, 2017, pp. 1-44.

CARRASCO ANDRINO, M., "Derechos fundamentales y legislación antiterrorista: ¿qué hemos perdido en el camino?", en Estudios Penales y Criminológicos, vol. XXXIX , 2019, pp. 59-105. https://doi.org/10.15304/ epc. 39.5766

CAROU GARCÍA, S., "Yihadismo y Derecho Penitenciario: la prevención del extremismo violento en prisión desde una perspectiva tratamental", en Anuario de Derecho Penal y Ciencias Penales, núm. 72, 2019, pp. 521-566.

CAROU GARCÍA, S., Primer grado penitenciario y Estado de Derecho: el estatus jurídico de los reclusos en régimen de máxima seguridad, Barcelona, Bosch, 2017.

CERVELLÓ DONDERIS, V., Derecho Penitenciario ( $4^{\mathrm{a}} \mathrm{ed}$.), Valencia, Tirant lo Blanch, 2016.

CILLUFO, F. y SAATHOFF, G., "Out of the Shadows. Getting ahead of prisoner radicalization", en The George Washington Homeland Security Policy Institute, Special Report, 2006, pp. 1- 38.

CLEAR, T. R., y SUMTER, M. T., "Prisoners, Prison and Religion", en Journal of Offender Rehabilitation, núm. 35, 2002, pp.125-156. https://doi.org/10.1300/ j076v35n03_07

CUTHBERTSON, I. M., "Prisons and the Education of Terrorist", en World Policy Journal, núm. 3, 2004, pp. $15-22$.

DE GIORGI, A., El gobierno de la excedencia. Postfordismo $y$ control de la multitud, Madrid, Traficantes de Sueños, 2006.

DE LA CORTE, L., “QQué sabemos y que ignoramos sobre la radicalización yihadista?", en MELLADO, A. (ed.), Islamismo yihadista: radicalización y contrarradicalización, Valencia, Tirant lo Blanch, 2015. 
DE LA CORTE, L., KRUGLANSKI, A., DE MIGUEL, J., SABUCEDO, J. M., y DÍAZ, D., "Siete principios psicosociales para entender el terrorismo" en Psicothema, núm. 19 (3), 2007.

DE LA CORTE, L. y JORDÁN, J., La yihad terrorista, Madrid, Síntesis, 2007.

DEL ROSAL BLASCO, B., “Hacia un Derecho Penal de la postmodernidad?, en Revista Electrónica de Ciencia Penal y Criminología, núm. 11 (08), 2009.

DEL OLMO VICÉN, N., "Construcción de identidades colectivas entre inmigrantes: ¿interés, reconocimiento y/o refugio?", en Reis: Revista española de investigaciones sociológicas, núm. 104, 2003, pp. 29-56. https:// doi.org/10.2307/40184568

DELLA PORTA, D. y DIANI, P., Los movimientos sociales, Madrid, CIS y Editorial Complutense, 2011.

DENZIN, N. K., Symbolic Interactionism and Cultural Studies: The Politics of Interpretation, Oxford, Blackwell, 1992.

DÍEZ RIPOLLÉS, J. L., Derecho penal español. Parte General. Valencia, Tirant lo Blanch, 2016.

DIX-RICHARDSON, F. y CLOSE, B. R., "Religion, the Community, and the Rehabilitation of Criminal Offenders", en Journal of Offender Rehabilitation, núm. 35, 2002, p. 87-106.

DUBAR, C., La crisis de las identidades: la interpretación de una mutación, Barcelona, Bellaterrra, 2002.

EDGWICK, M., "The concept of radicalisation as a source of confusion", en Terrorism and Political Violence, núm. 22 (4), 2010, pp. 479-494.

FERNÁNDEZ ABAD, C., "La resignificación de la pena de prisión y su renovada funcionalidad en el contexto de la «sociedad excluyente»: aproximación crítica al desplazamiento del ideal resocializador desde una lógica estructural", Revista de Derecho penal y Criminología, núm. 18, 2017, pp. 217-263. 
FOUCAULT, M., Los anormales, Barcelona, Akal, 2001.

FOUCAULT, M., Hay que defender la sociedad, Barcelona, Akal, 2003.

GALÁN MUÑOZ, A., "¿Leyes que matan ideas frente a las ideas que matan personas? Problemas de la nueva represión de los mecanismos de captación terrorista tras la reforma del código penal de la LO 2/2015", en Revista de Derecho Penal y Criminología, núm. 15, 2015, pp. 95-138.

GARCÍA CAVO, C. y REINARES, F., "Radicalización yihadista y asociación diferencial: un estudio cuantitativo del caso español”, en BERMEJO CASADO, R. y BAZAGA FERNÁNDEZ, I., Radicalización violenta en España. Detección, gestión y respuesta, Valencia, Tirant lo Blanch, 2019.

GARCÍA PABLOS, A., "La supuesta función resocializadora del Derecho penal: utopía, mito y eufemismo", en Anuario de derecho penal y ciencias penales, núm. 32, 1979, p. 645-700.

GOFFMAN, E., Internados. Ensayos sobre la situación social de los enfermos mentales, Buenos Aires, Amorrortu, 2001.

GONZÁLEZ COLLANTES, T., "Prisión y Terrorismo Yihadista: los FIES como medida penitenciaria de prevención de atentados, de adiestramiento y reclutamiento con fines terroristas", en ALONSO RIMO, A., CUERDA ARNAU, M. A. y FERNÁNDEZ HERNÁNDEZ, A. (dir.), Terrorismo, sistema penal $y$ derechos fundamentales, Valencia, Tirant lo Blanch, 2018.

GOODWIN, J., JASPER, J. M., y POLLETTA, F., Passionate Politics: Emotions and Social Movements, Chicago, University of Chicago Press, 2011.

HAMM, M., "Prison Islam in the age of sacred terror", en British Journal of Criminology, núm. 49, 2009. https:// doi.org/10.1093/bjc/azp035. 
HARCOURT, B., Against Prediction. Profiling, Policing, and Punishing in Actuarial Age, Chicago, The University of Chicago, 2007. https://doi.org/10.7208/chicago/9780226315997.001.0001

HERZOG-EVANS, M., "A comparision of two structured judgment tools for violent extremism and their relevance in the French context", en European Journal of Probation, núm.1, pp. 3-27. https://doi. org/10.1177/2066220317749140.

HORGAN, J., The psychology of terrorism, London, Routledge, 2005.

JORDÁN ENAMORADO, J., "Procesos de radicalización yihadista en España: Análisis sociopolítico en tres niveles", en Revista de Psicología Social, vol. 4, núm. 2, 2009, pp.197-216. https://doi. org/10.1174/021347409788041499.

KING, M., y TAYLOR, D. M., "The Radicalization of Homegrown Jihadists: A Review of Theoretical Models and Social Psychological Evidence", en Terrorism and Political Violence, núm. 4 (23), 2011, pp. 602-622. https://doi.org/10.1080/09546553.2011.587064.

KLANDERMANS, B., DE WEERD, M. S. y COSTA, M., "Injustice and adversarial frames in a supranational political context: Farmer's portesta in The Netherlands and Spain", en H. KRIESI, D. DELLA PORTA, y D. RUCHT (eds.), Social movements in a globalizing world, Londres, McMillan, 1990, pp.173-197. https://doi.org/10.1007/978-1-349-27319-5_8.

KRUEGER, A. B., y MALECKOVÁ, J., "Education, Poverty and Terrorism: is there a causal connection?", en Journal of Economic Perspectives, núm.17 (4), 2003, pp. 119-144. https://doi.org/10.3386/w9074.

KUNDNANI, A., "Radicalisation: the journey of a concept", en Race \& Class, vol. 54, pp. 3-25. https://doi. org/10.1177/0306396812454984. 
LAMARCA PÉREZ, C., "Régimen penitenciario y derechos fundamentales", en Estudios Penales y Criminológicos, núm.XVI, 1993, pp. 210-247.

LIEBLING, A. y MARUNA, S., "Introduction: the effects of imprisonment revisited", en A. LIEBLING y S. MARUNA (eds.), The Effects of Imprisonment, Nueva York, Routledge, 2006.

LLANO ORTIZ, J. C., El estado de la pobreza: seguimiento del indicador de riesgo de pobreza y exclusión social en españa 2008-2011, Madrid, EAPN-ES, 2017.

LOGAN, C. y LLOYD, M., "Violent extremism: a comparison of approaches to assessing and managing risk", en Legal and Criminological Psychology, núm.24, 2018, pp. 141-161. https://doi.org/10.1111/lcrp.12140.

MANDEL, D. R., "Radicalisation: What does it mean?", en T.M. PICK et al. (eds.), Home-grown terrorism: Understanding and addressing the root causes of radicalization (pp.101-112), Amsterdam, IOS Press, 2009.

MARÍ-KLOSE， P. y MARÍ-KLOSE， M., "¿Quién se empobrece y a quién estamos dispuestos a socorrer? Vulnerabilidad y solidaridad en un país en crisis", en $I I$ Jornadas aragonesas de sociología, Zaragoza, Prensas Universitarias, 2014.

MARRANCI, G., Faith, Ideology and Fear. Muslim Identities Within and Beyond Prisons, Londres, New York Continuum, 2011. https://doi.org/10.4324/9781003085393.

MARTÍNEZ MARTÍNEZ, M. A., "Estrategias contra el terrorismo islamista en prisión", en ALONSO RIMO, A., CUERDA ARNAU, M. A. y FERNÁNDEZ HERNÁNDEZ, A. (dir.), Terrorismo, sistema penal y derechos fundamentales, Valencia, Tirant lo Blanch, 2018.

McADAMS, D., TARROW, S., y TILLY, C., Dinámicas de la contienda política, Barcelona, Hacer, 2005.

MUÑOZ CONDE, F., "La resolución del delincuente: Análisis y Crítica de un mito", en S. MIR, La Reforma del Derecho Penal. Barcelona, Bellaterra, 1980. 
MAUGER, G., “"Jeunes de cités". Délinquance, émeutes et radicalisation islamiste", en Tempo Social, revista de sociología da USP, núm. 28 (2), 2016, pp. 39-56.

MELENDO PARDOS, M., CALLEJO GALLEGO, M. J., y LACRUZ LÓPEZ, J. M., Apuntes de Política Criminal, Madrid, Dykinson, 2019.

MERTON, R. K., "Social Structure and Anomie", en American Sociological Review, núm. 3 (5), 1939, pp. 672-682.

MOGHADDAM, F. M., "The Staircase to Terrorism: A Psychological Exploration”, en American Psychologist, núm.60 (2), 2005, pp. 161-169. https://doi. org/10.1037/0003-066x.60.2.161.

MULCAHY, E., MERRINGTON, S. y BELL, P., "The radicalisation of prison inmates. Exploring recruitment, religion and prisoner vulnerability", en Journal of Human Security, núm.1, 2013. https://doi.org/10.12924/ johs2013.09010004.

NEUMANN, P., "Prisons and Terrorism. Radicalisation and De-radicalisation in 15 Countries", en The International Centre for the study of radicalisation and political violence, 2010.

NEUMANN, P. y ROGERS, B., "Recruitment and Mobilisation for the Islamist Militant Movement in Europe", European Commission, 2007.

NISTAL BURÓN, J., "Radicalización en prisión", en BERMEJO CASADO, R. y BAZAGA FERNÁNDEZ, I., Radicalización violenta en España. Detección, gestión y respuesta, Valencia, Tirant lo Blanch, 2019.

NOGUER SALANAS, S., "La sociedad de acogida: retos para una convivencia normalizada", en J. D. GÓMEZ-QUINTERO, y C. MARCUELLO SERVÓS (eds.), Las políticas públicas y sociales en la encrucijada: incertidumbre, complejidad y cambio, Zaragoza, Universidad de Zaragoza, 2014.

O'CONNOR, T. P. y PERREYCLEAR, M., "Prison religion in Action and its influence on offender rehabilitation", 
en Journal of Offender Rehabilitation, núm. 35, 2002, pp. 11-23. https://doi.org/10.1300/j076v35n03_02.

O'MALleY, P., Crime and Risk, Londres, Sage Publications, 2010. http://dx.doi.org/10.4135/9781446251362.

PARK, R. E., La ciudad y otros ensayos de ecología urbana, Barcelona, Serval, 2005.

PEREIRA, V. B., SLATER, T., y WACQUANT, L., "Territorial Stigmatization in action", en Environment and Planing $A$, núm. 46, 2014. https://doi.org/10.1068/a4606ge.

RAMOS VÁZQUEZ, J. A., "Presente y futuro del delito de enaltecimiento y justificación del terrorismo", en Anuario da Facultade de Dereito da Univeridade da Coruña, núm. 12, 2008, pp. 771-793.

REINARES, F. y GARCÍA-CALVO, C., Estado Islámico en España, Madrid, Real Instituto Elcano, 2016.

REINARES, F. y GARCÍA-CALVO, C., Yihadismo y yihadistas en España, Madrid, Real Instituto Elcano, 2019.

RÍOS MARTÍN, J.C., Mil voces presas, Madrid, Universidad Pontificia de Comillas, 2001.

RÍOS MARTÍN, J. C., Manual de ejecución penitenciaria: defenderse en la cárcel, Madrid, Colex, 2014.

RÍOS MARTÍN, J. C., Cuestiones de Política Criminal. Funciones y miserias del sistema penal, Granada, Comares, 2017.

RIVERA BEIRAS, I., Política criminal y Sistema Penal: Viejas y nuevas racionalidades Punitivas, Barcelona, Anthropos y OSPDH, 2005.

RIVERA BEIRAS, I., "Actuarialismo Penitenciario. Su recepción en España”, en Revista Crítica Penal y Poder, núm. 9, 2015, pp. 102-144.

RUGGIERO, V., La violencia política: un análisis criminológico, Barcelona, Anthropos, 2009.

RUSHCHENKO, J., "Terrorist recruitment and prison radicalization: Assessing the UK experiment of separation centres", en European Journal of Criminology, Special Issue: Understanding European Jihadist: 
criminal, extremist or both, 2019, pp. 1-20. https://doi. org/10.1177/1477370819828946.

SABUCEDO, J. M., KLANDERMANS, B., RODRÍGUEZ, M., y FERNÁNDEZ, C., "Identidad social, valoración política y movilización colectiva en un contexto supranacional", en Revista de Psicología social, núm.15 (3), 2000, pp. 241-368. https://doi. org/10.1174/021347400760259703.

SAGEMAN, M., Understanding terrorist networks, Pennsylvania, University of Pennsyvania Press, 2004.

SAGEMAN, M., Leaderless Jihad: Terror Networks in the Twenty-First Century, Philadelphia, University of Pennsylvania Press, 2008.

SAGEMAN, M., "A Strategy for Fighting International Islamist Terrorists", en Annals of the American Academy of Political and Social Science, núm. 618 (1), 2008, pp. 223-231. https://doi.org/10.1177/0002716208317051.

SCHMID, A.P., Radicalisation, De-Radicalisation, Counter-Radicalisation: A Conceptual Discussion and Literature Review, The Hague, ICCT, 2013. https://doi. org/10.19165/2013.1.02.

SEDGWICK, M., "The concept of Radicalization as a Source of Confusion", en Terrorism and Political Violence, núm. 22, 2010, pp. 479-494. https://doi.org/10.1 080/09546553.2010.491009.

SILBER, M. D., y BHATT, A., Radicalization in the West: The Homegrown Threat, New York, NYPD Intelligence Division, 2007.

SILKE, A., "Holy Warriors: Exploring the Psychological Processes of Jihadi Radicalization", en European Journal of Criminology, vol. 5, núm. 1, 2008, pp. 99123. https://doi.org/10.1177/1477370807084226.

SILKE, A., "Terrorist, extremist and prison: an introduction to the critical issues", en SILKE, A. (ed.), Prisons, Terrorism and Extremism. Critical Issues in Management, Radicalisation and Reform, Londres, Routledge, 2014. 
SILKE, A. y VELDHUIS, T., "Countering Violent Extremism in Prisons: a review of key recent research and critical research gaps", en Perspectives on Terrorism, núm. 5, 2017.

SILVA SÁNCHEZ, J., Aproximación al Derecho Penal contemporáneo, Barcelona, Bosch Editorial, 1992.

SPALEK, B. y EL-HASSAN, S., "Muslim Converts in Prison", The Howard Journal, núm. 2, 2007, pp. 99-114. https://doi.org/10.1111/j.1468-2311.2007.00459.x.

SYKES, G., The society of captives: A Study of maximum security prison, Princeton, Princeton University Press, 2007.

TRUJILlO, H. M., JORDÁN, J. y GONZÁLEZ CABRERA, J., "Radicalization in prisons? Field research in 25 Spanish Prisons", en Terrorism and Political Violence, núm. 2, 2009. https://doi. org/10.1080/09546550903153134.

VALVERDE MOLINA, J., La cárcel y sus consecuencias: la intervención sobre la conducta desadaptada, Madrid, Editoral Popular, 1999.

WIKTOROWIC, Q., "Joining the Cause: Al-Muhajiroun and Radical Islam", en The Roots of Islamic Radicalism Conference, Yale University, 2003.

WRIGHT, S. C., TAYLOR, D. M., y MOGHADDAM, F. M., "Responding to Membership in a Disadvantaged Group: From Acceptance to Collective Protest", en Journal of Personality and Social Psychology, núm. 58 (6), 1990, pp. 994-1003. https://doi.org/10.1037/00223514.58.6.994. 